\title{
Impact of local data assimilation on tropical cyclone predictions over the Bay of Bengal using the ARW model
}

\author{
M. M. Greeshma ${ }^{1}$, C. V. Srinivas ${ }^{1}$, V. Yesubabu ${ }^{2}$, C. V. Naidu ${ }^{3}$, R. Baskaran ${ }^{1}$, and B. Venkatraman ${ }^{1}$ \\ ${ }^{1}$ Radiological Safety Division, Radiological Safety \& Environment Group, Indira Gandhi Centre for Atomic Research, \\ Kalpakkam 603102, India \\ ${ }^{2}$ National Atmospheric Research Laboratory, Gadanki 517112, India \\ ${ }^{3}$ Department of Meteorology \& Oceanography, Andhra University, Visakhapatnam 517112, India
}

Correspondence to: C. V. Srinivas (venkatasrinivasc@yahoo.com)

Received: 17 December 2014 - Revised: 17 May 2015 - Accepted: 21 May 2015 - Published: 03 July 2015

\begin{abstract}
The tropical cyclone (TC) track and intensity predictions over Bay of Bengal (BOB) using the Advanced Research Weather Research and Forecasting (ARW) model are evaluated for a number of data assimilation experiments using various types of data. Eight cyclones that made landfall along the east coast of India during 2008-2013 were simulated. Numerical experiments included a control run (CTL) using the National Centers for Environmental Prediction (NCEP) 3-hourly $0.5 \times 0.5^{\circ}$ resolution Global Forecasting System (GFS) analysis as the initial condition, and a series of cycling mode variational assimilation experiments with Weather Research and Forecasting (WRF) data assimilation (WRFDA) system using NCEP global PrepBUFR observations (VARPREP), Atmospheric Motion Vectors (VARAMV), Advanced Microwave Sounding Unit (AMSU) A and B radiances (VARRAD) and a combination of PrepBUFR and RAD (VARPREP+RAD). The impact of different observations is investigated in detail in a case of the strongest TC, Phailin, for intensity, track and structure parameters, and finally also on a larger set of cyclones. The results show that the assimilation of AMSU radiances and Atmospheric Motion Vectors (AMV) improved the intensity and track predictions to a certain extent and the use of operationally available NCEP PrepBUFR data which contains both conventional and satellite observations produced larger impacts leading to improvements in track and intensity forecasts. The forecast improvements are found to be associated with changes in pressure, wind, temperature and humidity distributions in the initial conditions after data assimilation. The assimilation of mass (radiance) and wind (AMV) data showed different impacts. While the motion vectors mainly
\end{abstract}

influenced the track predictions, the radiance data merely influenced forecast intensity. Of various experiments, the VARPREP produced the largest impact with mean errors (India Meteorological Department (IMD) observations less the model values) of $78,129,166,210 \mathrm{~km}$ in the vector track position, 10.3, 5.8, 4.8, 9.0 hPa deeper than IMD data in central sea level pressure (CSLP) and 10.8, 3.9, $-0.2,2.3 \mathrm{~m} \mathrm{~s}^{-1}$ stronger than IMD data in maximum surface winds (MSW) for $24,48,72,96 \mathrm{~h}$ forecasts respectively. An improvement of about $3-36 \%$ in track, 6-63\% in CSLP, 26-103\% in MSW and $11-223 \%$ in the radius of maximum winds in $24-96 \mathrm{~h}$ lead time forecasts are found with VARPREP over CTL, suggesting the advantages of assimilation of operationally available PrepBUFR data for cyclone predictions. The better predictions with PrepBUFR could be due to quality-controlled observations in addition to containing different types of data (conventional, satellite) covering an effectively larger area. The performance degradation of VARPREP+RAD with the assimilation of all available observations over the domain after $72 \mathrm{~h}$ could be due to poor area coverage and bias in the radiance data.

Keywords. Meteorology and atmospheric dynamics (General circulation; mesoscale meteorology; Tropical meteorology)

\section{Introduction}

Tropical cyclones (TC) are highly disastrous weather phenomena occurring in the tropical maritime environment. TCs form over warm tropical oceans, move towards land un- 
der the action of steering forces (Anthes, 1982; Gray, 2000, 1968) and cause damage from their extreme winds, heavy precipitation and storm surges. About $15 \%$ of global tropical cyclones occur in the North Indian Ocean (NIO), mainly distributed in the pre-monsoon (April-May) and post-monsoon (October-November) seasons (Asnani, 1994; Pattanaik and Rama Rao, 2009). Thermodynamic factors such as high sea surface temperature (SST), the presence of initial disturbances, the availability of mid-tropospheric humidity and weak vertical wind shear favour the development of cyclones in the NIO. The NIO is also the birthplace of the deadliest storms that have affected India and Bangladesh (WMO, 2011). Simulation studies of tropical cyclones, particularly those in the NIO basin are important as the coastal area surrounding the basin is heavily populated and often suffers huge losses of life and physical infrastructure from such storms. The movement of the TCs over the NIO is greatly variable due to the highly variable air-sea conditions (Raghavan and Sensarma, 2000). Advanced dynamic models have been increasingly used in addition to the synoptic and satellite surveillance techniques especially for guidance during changing environmental conditions in operational cyclone forecasting. Accurate numerical prediction of tropical cyclones is highly dependent on the representation of precise initial state, resolving the various scales of motion and the accurate representation of various physical processes. The models are also dependent on accurate specification of lower boundary conditions such as SST for realistically simulating the ocean-atmosphere interaction through air-sea fluxes on cyclone evolution (Jiang et al., 2008). While large-scale processes influence the motion of cyclones, the inner-core dynamics and its interaction with the environment determine the intensity of the system (Marks and Shay, 1998). With the advent of high-performance computing, advanced highresolution mesoscale models are employed to simulate the above processes for better prediction of tropical cyclones (e.g. Chen et al., 1995; Liu et al., 1997; Kurihara et al., 1998; Aberson, 2001; Wang, 2001; Krishnamurti, 2005; Braun et al., 2006; Fierro et al., 2009; Smith and Thomsen, 2010; Nolan et al., 2009; Gentry and Lackmann, 2010; among others).

The errors in tropical cyclone track prediction have steadily decreased over the past several decades due to the use of increasing horizontal and vertical model resolution, improvements in model physics and advanced data assimilation (Rogers et al., 2003; Gentry and Lackmann, 2010). Several model performance evaluation studies have been conducted for TC predictions in recent times (e.g. Prasad and Rama Rao, 2006; Davis et al., 2008; McNoldy et al., 2010; Yeh et al., 2012; Zhang et al., 2011; Gopalakrishnan et al., 2012; Srinivas et al., 2013; Krishna et al., 2012 among others) over different regions. In the USA, the Geophysical Fluid Dynamics Laboratory (GFDL) hurricane model and the Hurricane Weather Research and Forecasting (HWRF) model (Tallapragada et al., 2014) are widely used for opera- tional hurricane predictions. McNoldy et al. (2010) reported the HWRF model prediction errors for 2009 over Atlantic region to range from $92 \mathrm{~km}$ at $24 \mathrm{~h}$ to $518 \mathrm{~km}$ at $120 \mathrm{~h}$ for track forecasts and from $7 \mathrm{~m} \mathrm{~s}^{-1}$ at $24 \mathrm{~h}$ to $12 \mathrm{~m} \mathrm{~s}^{-1}$ at $120 \mathrm{~h}$ for intensity forecasts. Yeh et al. (2012), using an advanced version of HWRF, reported average track errors for the 2008 hurricane season with two domains (27 and $9 \mathrm{~km}$ horizontal resolution) to range from $42.6 \mathrm{~km}$ at $12 \mathrm{~h}$ to $260.9 \mathrm{~km}$ at $120 \mathrm{~h}$ forecasts and the corresponding mean intensity errors as $4.5 \mathrm{~m} \mathrm{~s}^{-1}$ at $12 \mathrm{~h}$ to $12.7 \mathrm{~m} \mathrm{~s}^{-1}$ at $120 \mathrm{~h}$. In all the above studies, the HWRF was run with a data assimilation system. The performance of the Advanced Research WRF (ARW) model for hurricanes in the Atlantic Basin was evaluated by Davis et al. (2008). The ARW predictions were shown to be generally competitive with and occasionally superior to the operational forecasts with GFDL, NOGAPS, UKMO, AVNO and other models. The India Meteorological Department (IMD) presently uses the models HWRF and ARW, in addition to the National Centers for Environmental Prediction (NCEP) quasi-Lagrangian model (QLM) for tropical cyclone predictions over the NIO region. The mean forecast errors for operational IMD QLM have been reported as 152, 235 and $375 \mathrm{~km}$ for 24,48 and $72 \mathrm{~h}$ forecasts respectively (Prasad and Rama Rao, 2006; Tyagi et al., 2010; Rama Rao et al., 2010). Srinivas et al. (2013a) assessed the performance of the ARW model for 21 cases of cyclones that formed between 2000 and 2011 with a horizontal resolution $(27,9 \mathrm{~km})$ similar to operational configuration of IMD WRF and NCEP HWRF for TC predictions over Bay of Bengal (BOB). The mean forecast errors were reported as $-2-15 \mathrm{hPa}$ for central sea level pressure (CSLP), $1-22 \mathrm{~m} \mathrm{~s}^{-1}$ for maximum surface winds (MSW) and $170-250 \mathrm{~km}$ for vector track positions corresponding to $24-72 \mathrm{~h}$ predictions. In another recent study, Raju et al. (2012) examined the performance of WRF considering four cyclones during 2007-2010 and reported the mean landfall position error as about $98 \mathrm{~km}$. Das et al. (2014) studied the performance of HWRF over the NIO region considering nine major cyclones over the NIO and reported the average track errors as $83 \mathrm{~km}$ at $12 \mathrm{~h}$ to $319 \mathrm{~km}$ at $72 \mathrm{~h}$ and improvements of $7-15 \%$ in $36-72 \mathrm{~h}$ predictions over the IMD operational forecasts. The above studies show good potential in the WRF model for TC predictions over the NIO region. However, due to large uncertainties in the movement prediction of cyclonic storms just before the landfall, especially in the BOB, there is a growing demand for further improvement in the operational forecasts.

In the numerical simulation of TCs, precise specification of initial conditions (location, radius, central pressure and tangential and vertical winds) is very important as their initial errors grow with integration and ultimately influence the model forecasts. The current operational global model analyses, which serve as the initial conditions for regional models, are available at 0.25 and $0.5^{\circ}$ horizontal resolutions and may not be adequate to resolve the initial cyclone position, vortex and 3-D structure in the regional models. The uncertainty 
can be reduced using observational assimilation (Wu et al., 2007; Park et al., 2008; Pu, 2009; Kim et al., 2010). There has been a considerable increase in the number of observations, both from conventional (surface and upper air) and satellite (cloud motion vectors, scatterometer winds, radiances sensitive to temperature or humidity profile) sources over the NIO region in the recent times. The increase in observational density allows operational centres and researchers to use highresolution grid over the specified region for improving the predictions.

The IMD presently runs the triple nested domain WRF (ARW) with three-dimensional variational assimilation (3DVar) with a horizontal resolution of 27,9 and $3 \mathrm{~km}$ twice daily (00:00 and 12:00 UTC) using the initial and boundary conditions taken from IMD Global Forecasting System (GFS) 574/L64 and with a single assimilation cycle (Roy Bhowmik, 2013). The impact of data assimilation on simulation of TCs over the NIO has been studied by several authors in the last decade (e.g. Singh et al., 2008, 2011, 2012a; Xiao et al., 2009; Krishna et al., 2010, 2012; Srinivas et al., 2010; Prashant et al., 2012; among others). However, most of these were individual case studies using various model configurations and with significant differences in the results due to the use of various data sources (satellite, radar, conventional, etc.) and due to not describing the quantitative improvements statistically. A few recent works on the NIO (e.g. Srinivas et al., 2012; Yesubabu et al., 2013, 2014) have quantified the relative impacts of conventional and satellite observations using the WRF Data Assimilation system (WRFDA) on the improvements of cyclone track and intensity predictions using a single assimilation cycle (cold-starting mode). The variational data assimilation technique would be effective when the distance between the model first guess and the observations is large and the cost function is iteratively minimized (Ide et al., 1997; Barker et al., 2004). Since most of the observations collected over the NIO region are already assimilated in GFS, using them again in the WRFDA for the same analysis time may lead to over-tuning of analysis towards observations. Even though various types of observations are available use of all the data may not result in improvement of the analysis. This raises an important question as to which type of observation (surface, ship, buoys, radar, upper air and satellite) provides major improvements in predictions. In connection with this, a few recent works (Srinivas et al., 2010, 2012, 2013b) indicate the satellite microwave remote-sensing-based scatterometer winds and MODIS temperature and humidity profiles provide larger impacts relative to the conventional data in assimilation. However, the surface observations may also be useful when combined with other 3-D data assimilation systems such as 3D-Var (Yesubabu et al., 2013; Singh et al., 2013). Recent studies on direct assimilation of satellite radiance observations (Singh et al., 2012 b) on atmospheric parameters (temperature, humidity) have been shown to improve the intensity and track predictions through altering the large-scale thermodynamic struc- ture of the atmosphere. One of the advantages of 3D-Var is direct assimilation of satellite-measured radiances without the need to convert to model variables. While most of the global operational centres use radiance observations like Advanced Microwave Sounding Unit (AMSU) A and B for assimilation in their regional models, its use is still in the initial stage in India (Roy Bhowmik, 2013). Though it is rare to assimilate only Atmospheric Motion Vectors (AMV) and radiances (RAD) in operational forecasting, it is required to understand their relative impact on the predictions for operational benefits. Presently, weather prediction centres use quality-screened observations (both conventional and satellite data) for operational predictions. The preceding review shows that there is a need for an assessment of WRF with cyclic mode assimilation (warm start) for a large number of cyclones using various types of observations to describe the quantitative skill for TC predictions over the NIO region. Some of the interesting scientific issues in this context are (i) whether observation assimilation always leads to improvements over simple downscaling of global model forecasts; (ii) whether combining the special observations like satellite radiances with commonly available quality-screened observations leads to additional positive impact; and (iii) how mass/wind observations impact different properties of TCs (track, wind speed, rainfall, etc.). The objective of this study is to assess the skill of the ARW model with observation assimilation in cyclic mode for cyclone track and intensity predictions over the $\mathrm{BOB}$ of $\mathrm{NIO}$ region and to address the above aspects by selecting suitable data for assimilation. Towards this objective, data assimilation experiments are conducted for a set of eight cyclones using different sources of data, i.e. AMV, satellite-measured radiances and the operationally processed PrepBUFR observations which contain several types of data (surface, ship, buoys, upper air, AMV, scatterometer winds, etc.). The results are statistically evaluated for different storm parameters to assess the model skill. Section 2 provides a brief description of the storms selected for the study, details of the model, configuration and numerical experiments and it describes the data used and the model initialization. Section 3 provides detailed results for recent very severe cyclone Phailin (2013) followed by quantitative track and intensity errors for all eight cyclones.

\section{Methodology}

\subsection{Overview of selected tropical cyclones}

In the present study, eight cyclones (Khaimuk, Laila, Jal, Thane, Nilam, Phailin, Lehar and Madi) originated in the BOB in the period 2008-2013 (Table 1) are considered to assess the ARW performance using variational data assimilation in cyclic mode. Among the eight cases, Phailin, Lehar, Madi and Thane are very severe cyclones, Jal and Laila are severe cyclones and Nilam and Khaimuk are cyclonic storms. 


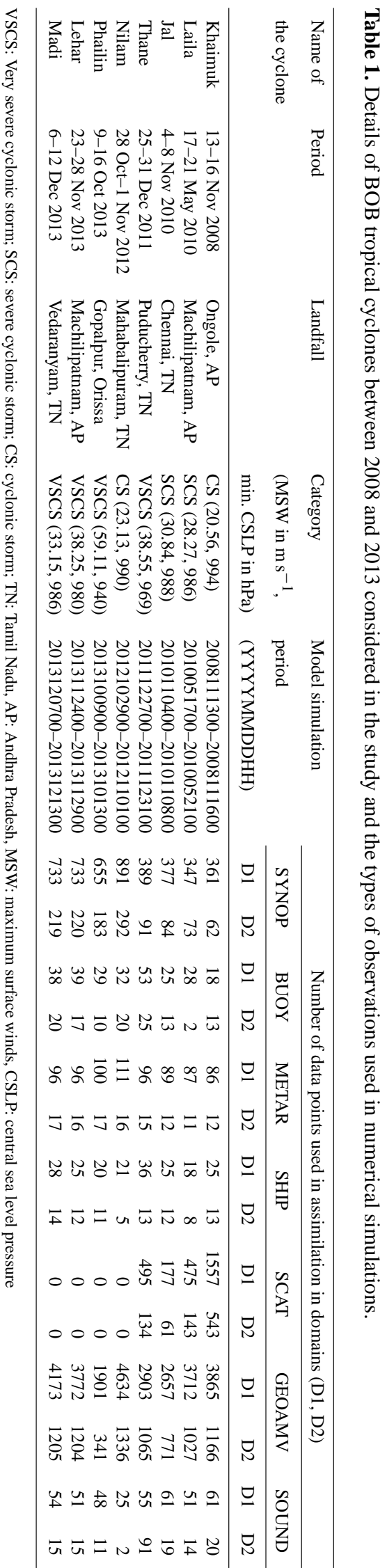

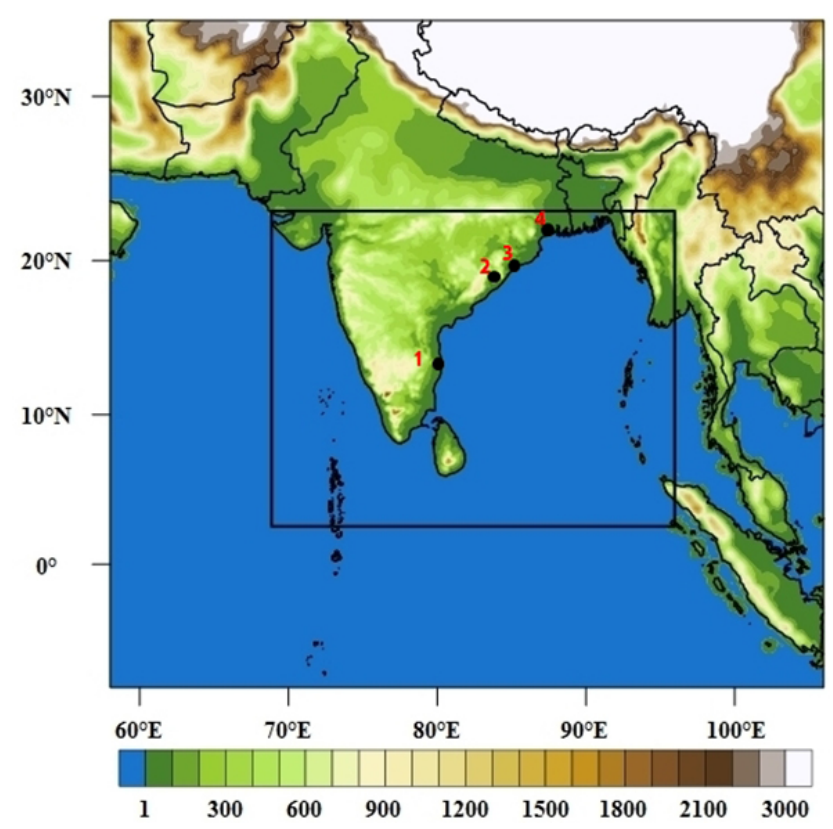

Figure 1. Modelling domains used in ARW for cyclone simulations. The shading gives the terrain height in metres. Numbers $1-4$ denote locations. 1: northern Tamil Nadu, 2: northern coastal Andhra Pradesh, 3: southern coastal Orissa, and 4: West Bengal.

The duration of cyclonic activity, landfall position and category of each cyclone have been listed in Table 1. Among these eight cyclones, Khaimuk, Laila and Thane originated in the south-eastern BOB, Jal formed over the southern BOB, Nilam originated over central BOB, Madi formed in the south-western BOB, Phailin formed over the eastern central $\mathrm{BOB}$ and Lehar over the Andaman Sea from a remnant cyclonic circulation over the South China Sea. The detailed description of each cyclone is given in the bulletins of Regional Specialized Meteorological Centre (RSMC) Tropical Cyclones, New Delhi (India Meteorological Department, 2009-2014).

\subsection{Numerical experiments}

The National Centre for Atmospheric Research (NCAR) non-hydrostatic primitive equation mesoscale atmospheric model ARW v3.4 model is used for cyclone predictions in this study. The ARW is based on Eulerian mass dynamical core with accurate numerics and advanced physics. It uses terrain-following vertical coordinates and an Arakawa Ctype staggered horizontal grid. The model has several options for spatial discretization, diffusion, nesting, lateral boundary conditions, data assimilation and physics (Skamarock et al., 2008). The ARW for tropical cyclone prediction over the NIO region was customized by simulating 21 past cyclones (Srinivas et al., 2013a) with two nested domains and with physics sensitivity tests. The same domain and physics configuration is adopted for TC predictions over BOB in 
the present study. Two interactive nested domains are used (Fig. 1) with coarse domain covering a larger region of NIO with $27 \mathrm{~km}$ grid spacing and the inner domain covering the BOB and its neighbourhood region with $9 \mathrm{~km}$ grid spacing. A total of 35 vertical levels are used with the model top at $100 \mathrm{hPa}$. The model topography such as terrain elevation, land-use and soil types for the 27 and $9 \mathrm{~km}$ resolution domains are derived from the USGS data at arc $5^{\prime}$ and $2^{\prime}$ resolutions. The model physics options for both 27 and $9 \mathrm{~km}$ domains consisted of Lin mixed phase scheme (Lin et al., 1983) for cloud microphysics, a rapid radiation transfer model (RRTM) for long-wave radiation (Mlawer et al., 1997), Dudhia scheme (Dudhia, 1989) for shortwave radiation, MM5 similarity theory for surface layer, the Yonsei University non-local diffusion (Hong et al., 2006) for boundary layer turbulence, the new Kain-Fritsch mass flux scheme (Kain, 2004) for convection and the NOAH scheme for land surface processes (Chen and Dudhia, 2001). Simulations for each cyclone are performed with initial conditions corresponding to depression stage, and the model is integrated up to a period of attaining the weakening phase subsequent to landfall. The model initialization time for various cyclones for an integration period of $96 \mathrm{~h}$ (4 days) is provided in Table 1. For each cyclone, two sets of experiments are conducted: one without assimilation and the other with assimilation using 3D-Var.

\subsection{Brief description of the assimilation system}

The three-dimensional variational assimilation (3D-Var) incorporated into WRF (Barker et al., 2011) is used in this study. With 3D-Var, many types of observations including satellite radiances can be assimilated (Liu and Barker, 2006). In 3D-Var, an "optimal" estimate of the atmospheric state is obtained for a given analysis time by iteratively minimizing the solution of a cost function (Ide et al., 1997; Barker et al., 2004, 2011; Courtier et al., 1998; Kalnay, 2003):

$$
\begin{aligned}
J(x)= & J^{\mathrm{b}}+J^{0}=\frac{1}{2}\left(\boldsymbol{x}-\boldsymbol{x}^{\mathrm{b}}\right)^{T} \mathbf{B}^{-1}\left(\boldsymbol{x}-\boldsymbol{x}^{\mathrm{b}}\right) \\
& +\frac{1}{2}\left(\mathbf{y}-\mathbf{y}^{0}\right)^{T}(\mathbf{E}+\mathbf{F})^{-1}\left(\mathbf{y}-\mathbf{y}^{\mathrm{o}}\right) .
\end{aligned}
$$

Here, $J(x)$ is scalar cost function, $\boldsymbol{x}$ is the model state vector and represents a state vector describing the atmospheric and surface variables, $\boldsymbol{x}^{\mathrm{b}}$ is a background vector that is usually obtained from a previous forecast, $\mathbf{y}^{\mathbf{o}}$ is observation data, $\mathbf{B}$ is background error covariance matrix, $\mathbf{E}$ is observation error covariance matrix and $\mathbf{F}$ is the representivity error covariance matrix. The solution of the Eq. (1) represents a minimum variance estimate of the true state of the atmosphere. The representivity error which is the inaccuracies introduced in the observation operator, $H$, is defined by $\mathbf{y}=H \boldsymbol{x}$. Here, $H$ transforms model variables to observation quantities $\mathbf{y}$. For radiance data assimilation, $H$ uses a fast radiation transfer model (RTM) that calculates radiances from inputs of at- mospheric state $\boldsymbol{x}$. The analysed model state, $\boldsymbol{x}$, is thus produced by combining observations, model forecasts, their respective errors and physical laws. The quality of the variational assimilation system also depends on the accuracy of the prescribed model errors (Rakesh et al., 2010; Routray et al., 2014). B is estimated using the standard National Meteorological Center (NMC) method (Parrish and Derber, 1992), wherein the forecast error covariances are approximated using forecast differences that are valid for the same time. Following this method, $\mathbf{B}$ can be written as

$\mathbf{B}=\overline{\varepsilon \varepsilon^{T}} \cong \overline{X^{\prime} X^{\prime T}} \cong \overline{\left(x_{t}^{2}-x_{t}^{1}\right)\left(x_{t}^{2}-x_{t}^{1}\right)^{T}}$,

where $X^{\prime}$ is estimated as the difference between two forecasts $\left(\boldsymbol{x}_{t}^{2}=24 \mathrm{~h}, \boldsymbol{x}_{t}^{1}=12 \mathrm{~h}\right.$ forecasts, i.e. $T+24$ minus $\left.T+12\right)$ and the overbar denotes an average over time and geographical area. In this method, it is assumed that background error is statistically well represented by a model state perturbation $X^{\prime}$. The calculation of $\mathbf{B}$ included 60 forecast samples, i.e. $12 \mathrm{~h}$ forecasts throughout November, 2007. These monthlong series of $24 \mathrm{~h}$ minus $12 \mathrm{~h}$ forecasts were used as model perturbations to generate B using NMC method for the study domain configuration.

\subsection{Data and model initialization}

In the control run (CTL) of each cyclone, the model is initialized with NCEP GFS $0.5^{\circ} \times 0.5^{\circ}$ analysis. The time-varying lateral boundary conditions for the outer domain as well as lower boundary SST data are defined at every $3 \mathrm{~h}$ interval from the GFS forecasts. The data used for the 3D-Var experiments are the first guess or background field (WRF $6 \mathrm{~h}$ forecast) background error covariance matrix estimated using NMC method and various observation sources. The time window allowed for gathering observations is $\pm 3 \mathrm{~h}$. Yesubabu et al. (2014) conducted 3D-Var cold-starting mode assimilation experiments for a set of cyclones in the BOB using NCEP PrepBUFR data and GFS analysis as background and reported marginal improvements in track and intensity predictions over CTLs. The reason for meager improvements in predictions using 3D-Var cold-starting mode experiments could be the re-use of same observations in mesoscale model leading to over-tuning the analysis towards observations. Hence in this study, to avoid the over-tuning issue, WRF initialized in 3D-Var experiments at 00:00 UTC using the GFS analysis is first integrated for $6 \mathrm{~h}$ to provide a first guess field at 06:00 UTC for the 3D-Var data assimilation. Then, observations are assimilated in two forecast cycles (06:00, 12:00 UTC) and WRF is integrated from 12:00 UTC to produce $84 \mathrm{~h}$ forecasts for the five cyclones Laila, Jal, Thane, Phailin and Madi, $60 \mathrm{~h}$ forecasts for Khaimuk and Nilam and $108 \mathrm{~h}$ for Lehar. Recent studies (Kuni et al., 2010; Singh et al., 2012a; Hsiao et al., 2012) considered $12 \mathrm{~h}$ duration of assimilation as sufficient enough for the mesoscale model to warm up, i.e. develop its own small-scale features for cyclone prediction. Kuni et al. (2010) studied the impact of 

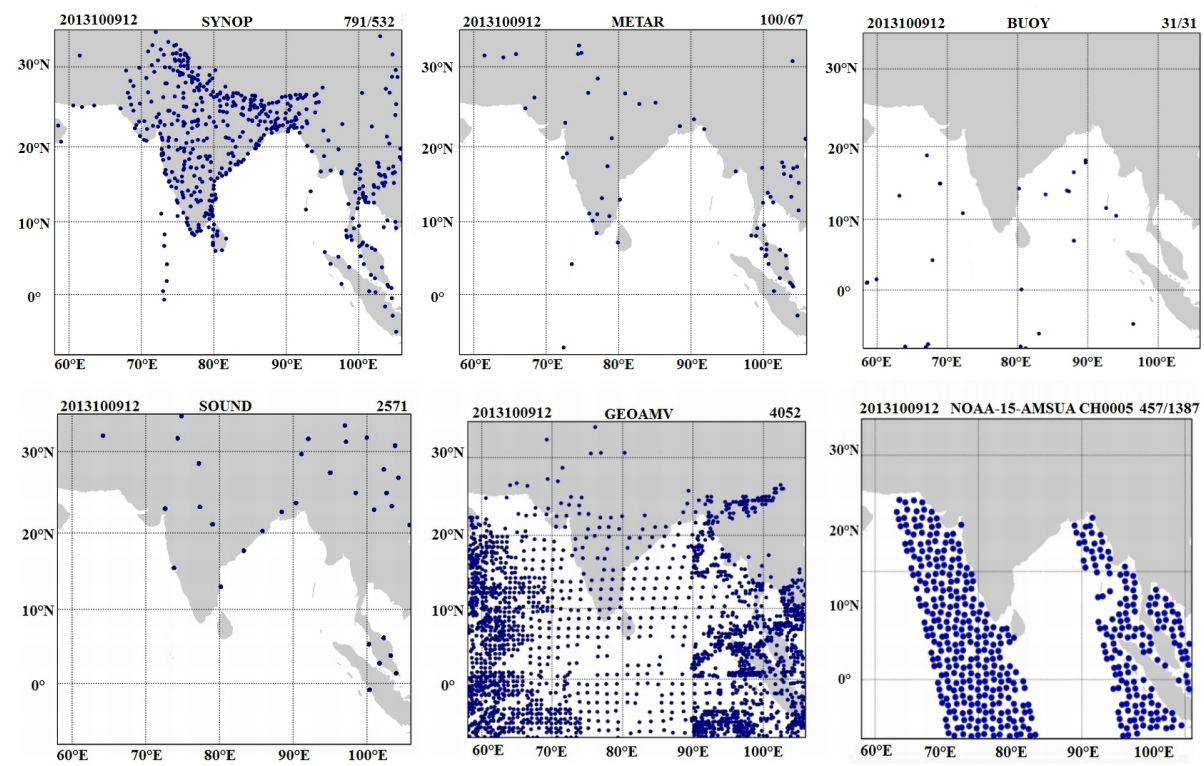

Figure 2. Spatial distribution of different observations used in assimilation experiment VARPREP+RAD for Phailin at 12:00 UTC 9 October 2013.

12 and $24 \mathrm{~h}$ data assimilation period on the simulation of tropical cyclone Nargis in the BOB. It has been shown that the cycling technique alone cannot ensure improvement, but data availability is the major factor which decides the behaviour of the assimilation system. It has been pointed out that the $24 \mathrm{~h}$ cycle cannot give much improvement compared to the $12 \mathrm{~h}$ cycle because of less satellite data coverage, which is the main source of data over the oceans. Hsiao et al. (2012) considered a two-cycle $12 \mathrm{~h}$ assimilation duration as a warm-up period for reducing the model imbalance and derive better initial condition for cyclone predictions. A $6 \mathrm{~h}$ warm-up period is used at NCAR (http://www.dtcenter. org/config/v3.6.1/ARW_PS4.4.4.91.2.1.1/index.php) for operational mesoscale model predictions. Based on the above studies, a total duration of $12 \mathrm{~h}(2 \times 6 \mathrm{~h}$ cycles $)$ is considered for local assimilation cycle in the present study.

Data used for assimilation include operationally available PrepBUFR global observations from the NCEP Atmospheric Data Project (ADP) archives and Advanced Microwave Sounding Units (AMSU) radiances (A and B) influenced by atmospheric temperature and humidity profiles. AMSU-A and AMSU-B are multi-channel radiometers on the National Oceanic and Atmospheric Administration (NOAA) polar orbiting series of satellites of 15 and 5 channels respectively. The AMSU-A radiometer has nominal spatial resolution at nadir of $48 \mathrm{~km}$ with an instantaneous field of view (IFOV) of $3.3^{\circ}$. The antenna provides a cross-track scan, scanning $\pm 48.3^{\circ}$ from nadir with a total of 30 Earth fields of view per scan line. This instrument completes one scan every $8 \mathrm{~s}$. The instrument AMSU-B is a continuous line scanning, total power microwave radiometer. The instrument has an IFOV of $1.1^{\circ}$ with nominal spatial resolution at nadir of $16 \mathrm{~km}$. The antenna provides a cross-track scan, scanning $\pm 48.95^{\circ}$ from nadir with a total of 90 Earth fields of view per scan line. It completes one scan every $8 / 3 \mathrm{~s}$. For the present study the radiance observations from NOAA 15, 16, 17 and 18 are used. After the quality screening, only observations from NOAA 15 AMSU-A, NOAA 16 AMSU-A, NOAA 16 AMSU-B and NOAA 18 AMSU-A are used. The PrepBUFR data comprise land surface (SYNOP, METAR), marine surface (buoy, ships), radiosonde, pilot-balloon and aircraft reports from the Global Telecommunications System (GTS), AMV from geostationary satellites, profiler- and radar-derived winds, Special Sensor Microwave Imager (SSM/I) oceanic winds and satellite wind data from National Environmental Satellite, Data, and Information Service (NESDIS) which are operationally collected by the NCEP. Details about the data are available at http://rda.ucar.edu/datasets/ds337.0.

The PrepBUFR data contain quality-screened (filtering of observations based on the error limit as well as background and duplication) data set prepared by NCEP based on the majority of conventional and satellite observational data for assimilation into the various NCEP analyses (Keyser, 2010). The distribution of observations varied for each cyclone case depending on the satellite pass and availability of upper-air observations, etc. The spatial distribution of the locations where different types of observations are available for assimilation is presented in Fig. 2 for Phailin at 12:00 UTC 9 October 2013 as an example. The community radiative transfer model (CRTM) available in 3D-Var (Han et al., 2006; Liu et al., 2006) is used for direct ingestion of AMSU radiance data in the model. The CRTM can simulate channel-specific radiances for infrared and microwave sensors. It also permits the computation of radiance gradients (Jacobians), with re- 
spect to the temperature and moisture variables, as required for assimilation of radiance in numerical weather prediction (NWP) models. The radiance biases can be expressed as the linear combination of predictors which leads to a modified forward operator

$\widetilde{H}(\boldsymbol{x}, \beta)=H(x)+\beta_{0}+\sum_{i=1}^{N_{\mathrm{p}}} \beta_{i} p_{i}$,

where $\beta_{0}$ is a constant component of total bias, and $p_{i}$ and $\beta_{i}$ are the $i$ th of $N_{\mathrm{p}}$ predictors and corresponding bias correction coefficients respectively (Liu et al., 2012). The bias correction coefficients of $\beta$ are channel dependent and can be estimated offline (Harris and Kelly, 2001) or updated by using a variational bias correction scheme (Derber and Wu, 1998). In the present study, bias correction is carried out using the inbuilt bias correction coefficients for the first cycle. In the subsequent cycles, the bias correction coefficients from the previous cycle are used. Also, the lateral and lower boundary conditions are updated using the output from the previous cycle and observations used for each cycle. Five sets of experiments are conducted for each cyclone case. The first one is a CTL and the rest are assimilation experiments named as VARAMV, VARRAD, VARPREP and VARPREP+RAD using AMV, AMSU radiances, all PrepBUFR observations and PrepBUFR observations along with AMSU radiances respectively designed to assess the impact of various observation sources.

For validation of simulated track and intensity parameters, the IMD best track parameters are used. The azimuthally averaged temperature anomaly, tangential winds and the radius of maximum wind (RMW) from the model are compared with the data from Cooperative Institute for Research in the Atmosphere (CIRA). The CIRA data also provides maximum sustained wind (MSW) and CSLP and gives a quantitative structure of cyclones from Multi-Platform Tropical Cyclone Analysis products (Knaff et al., 2011) created by NOAA/NESDIS/STAR. The CIRA wind products for TCs are derived based on AMSU winds, cloud-drift/IR/WV (water vapour) winds, IR proxy winds and Quick Scatterometer/Advanced Scatterometer (QuikSCAT/ASCAT) winds. The structure of the convective rain bands is compared with reflectivity measured by Doppler weather radar (DWR) and the spatial rainfall distribution is compared with Tropical Rainfall Measuring Mission (TRMM) 3B42 V7 data sets (Huffman et al., 2007). Simulated maximum reflectivity from all experiments is compared with reflectivity images of IMD DWR.

\section{Results and discussion}

The results of simulations are discussed by illustrating qualitative improvements for intensity and track parameters for the case of Phailin followed by the quantitative analysis of errors for all eight cyclones. Phailin is chosen for showing qualitative comparisons as it was the strongest TC of the eight cyclones of this study. All the results are analysed from high- resolution $(9 \mathrm{~km})$ model domain. The analysis increment obtained using data assimilation in the wind field, temperature and relative humidity in both horizontal and vertical planes is discussed below. The improvement with data assimilation from CTL runs is described in terms of error in CSLP, MSW, RMW, track positions, structure and rainfall prediction with respect to error reduction in the initial conditions.

\subsection{Results for Phailin}

A detailed analysis on the scatter of observations with respect to background/analysis after assimilation, differences in initial conditions and prediction errors in CTL and 3D-Var experiments, improvements in structure parameters are presented below for the Phailin.

\subsubsection{Fit of various observations to the analysis and first guess}

To illustrate how much the different sources' assimilated observations modified the first guess fields, two scatter plots are drawn for each source (Fig. 3). The first scatter plot compares the assimilated observations with the model first guess (shown in blue) and the second scatter plot after 3D-Var analysis for the case of VARPREP+RAD (shown in red) for the thermodynamic and dynamic parameters (water vapour $\left(Q_{\mathrm{v}}\right)$, temperature $(T)$, and wind components $(U$ and $V)$ ) from the model first domain. Successful assimilation reduces the departures of analysis from observations $(\mathrm{O}-\mathrm{A})$ relative to the departures of first guess from observations $(\mathrm{O}-\mathrm{B})$, thereby bringing the analysis towards observations. The plots show less scatter after assimilation indicating significant reduction of departures after 3D-Var analysis (VARPREP+RAD) compared to the first guess, i.e. decrease of $\mathrm{O}-\mathrm{A}$ with respect to $\mathrm{O}-\mathrm{B}$. With assimilation of the surface synoptic data, the mean departures in the $2 \mathrm{~m}$ temperature are reduced from -0.349 to $0.013 \mathrm{~K}$ in the first-guess fit to the analysis fit. With assimilation of METAR data, the mean departures in surface temperature are reduced from -0.458 to $-0.186 \mathrm{~K}$ and the root mean square error (RMSE) is reduced from 2.101 to $1.610 \mathrm{~K}$ in the first-guess fit to the analysis fit, suggesting analysis improvement of $\sim 25 \%$. From the assimilation of surface observations, no remarkable changes were observed in the wind and water vapour fields (not shown). Since the conventional in situ observations over the ocean are scarce, satellite observations are the only source that can be depended upon. The assimilation of AMV substantially decreased the wind departures and the reductions in the zonal and meridional wind departures are 0.55 and $0.5 \mathrm{~m} \mathrm{~s}^{-1}$ in terms of bias and RMSE, respectively indicating an improvement of $15 \%$ in analysis, at all model levels. Thus, it is obvious that inclusion of AMV has made significant changes 

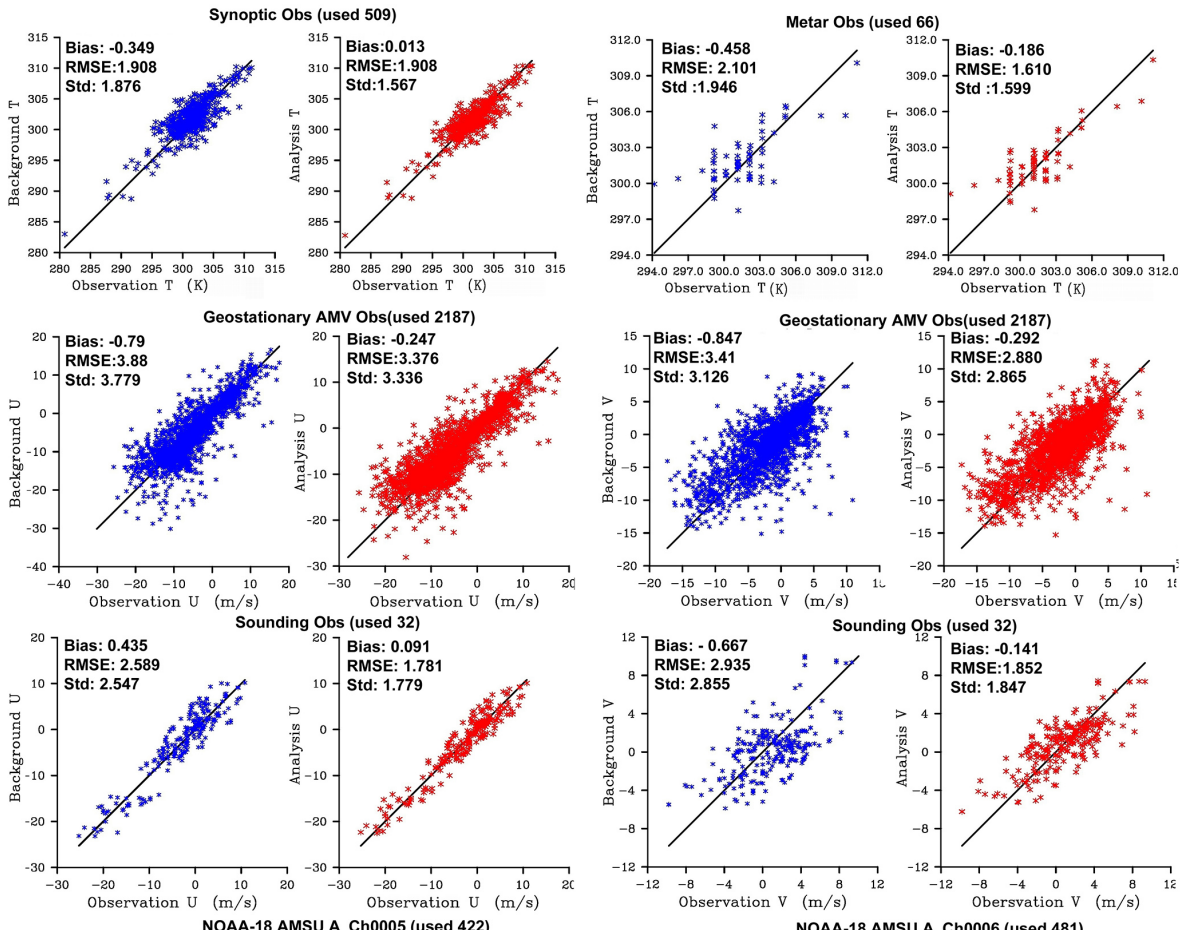

Nding Obs (used 32)
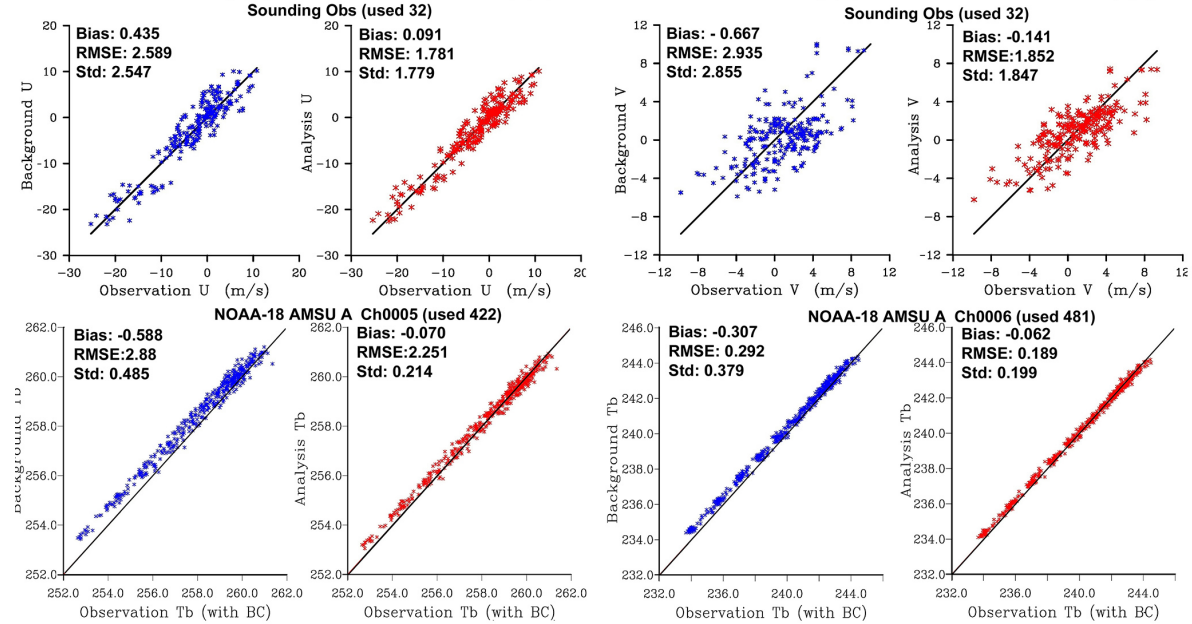

Figure 3. Scatter plot of observations versus first guess (in blue) and 3D-Var analysis (in red) for temperature and wind for VARPREP+RAD corresponding to the analysis time 12:00 UTC 9 October 2013.

in the wind field over the ocean, which has a great impact on TC simulations. With assimilation of profile observations (radiosonde) the RMSE of departures reduced from the firstguess fit to the analysis fit by $0.80-1.0 \mathrm{~m} \mathrm{~s}^{-1}, 0.06 \mathrm{~K}$ and $0.06 \mathrm{~g} \mathrm{~kg}^{-1}$ for $U$ and $V$ components, temperature and water vapour mixing ratio respectively at all levels (the scatter plots for temperature and water vapour are not shown). While assimilating AMSU-A and AMSU-B, major differences are found for channels 5 and 6 of NOAA 18 AMSU-A, with RMSE reductions of 0.63 and $0.1 \mathrm{~K}$ and bias reductions of 0.51 and $0.25 \mathrm{~K}$ respectively in temperature, from the firstguess fit to the analysis fit. The reduction of $\mathrm{O}-\mathrm{A}$ for all these parameters indicates that observations are given sensible weights in the analysis.

\subsubsection{Differences in the initial conditions in CTL and VAR experiments}

To assess the extent of structural changes and incremental improvement in the model fields after assimilation, the spatial distribution of initial temperature, moisture, sea level pressure and wind field from the CTL and the difference field VAR - CTL are analysed at the end of the second cycle of assimilation (12:00 UTC 9 October 2013). Figure 4 shows the differences between CTL, each of 3D-Var experiments in sea level pressure, and wind at $10 \mathrm{~m}$. The CTL (Fig. 4a) indicates a low pressure vortex located in the eastern central BOB south-west of Myanmar at about $14^{\circ} \mathrm{N}$, $92.5^{\circ} \mathrm{E}$ with a CSLP of $994 \mathrm{hPa}$ and a maximum wind of $20 \mathrm{~m} \mathrm{~s}^{-1}$. Analysis differences (VAR - CTL) show an increase in the anticlockwise winds in the region of the cyclone. A dipole appears due to the changes in the central location of the TC in the VAR experiments. The negative side of the dipole (-ve CSLP changes) indicates the position of the cyclone in 3D-Var experiments and the positive side (+ve CSLP change) shows the position in CTL experiment. The large wind increments $\left(\sim 5-10 \mathrm{~m} \mathrm{~s}^{-1}\right)$ in VARPREP and VARPREP+RAD indicate a stronger cyclonic vortex in these cases relative to VARAMV and VARRAD. The changes in winds and pressure distribution in VARPREP and VARPREP+RAD could be attributed to the 

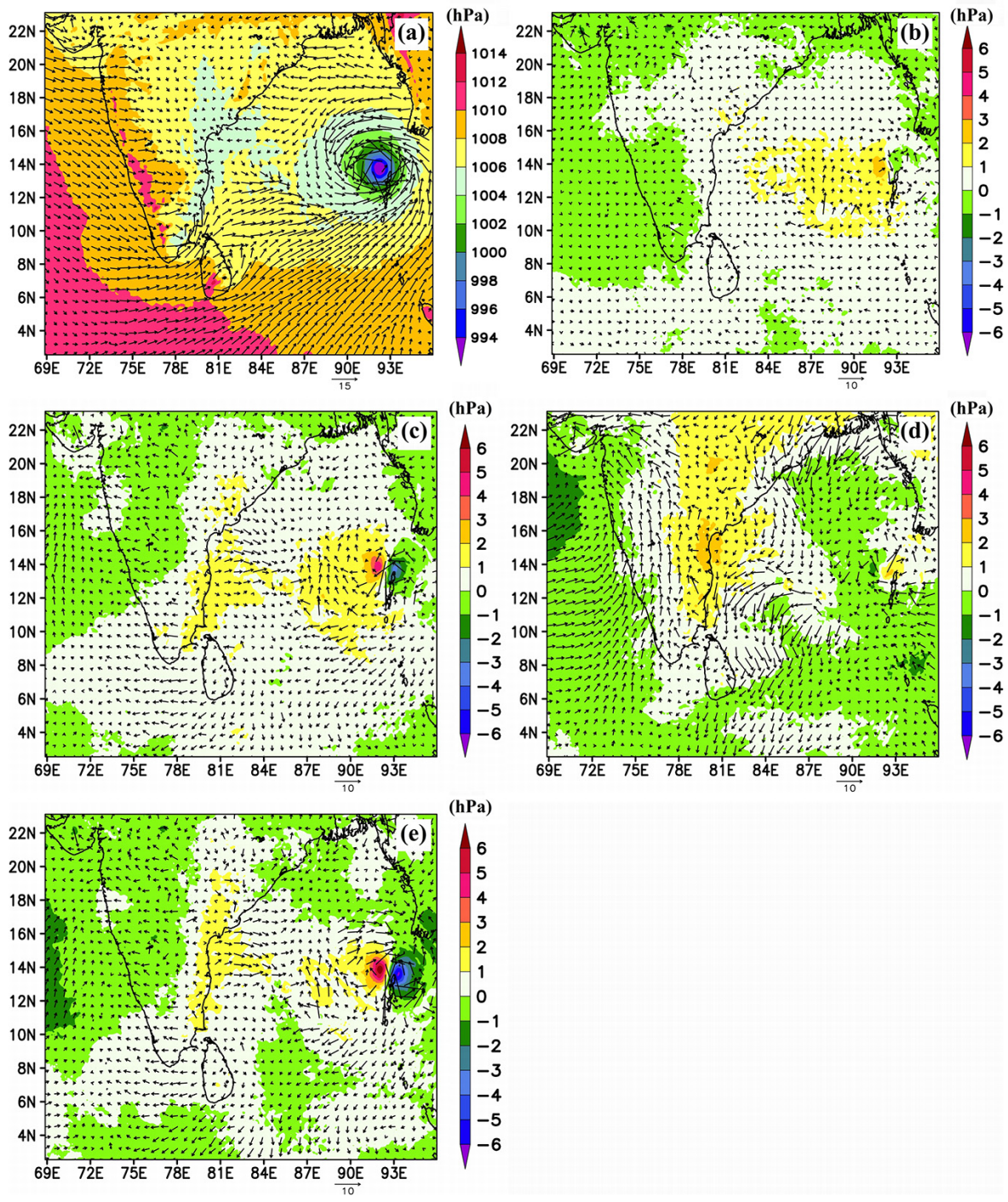

Figure 4. Field of (a) initial sea level pressure (shaded), surface (10 m level) wind flow pattern in CTL and analysis difference (VAR - CTL) in (b) VARAMV, (c) VARPREP, (d) VARRAD and (e) VARPREP+RAD for Phailin at 12:00 UTC 9 October 2013.

assimilation of surface synoptic, scatterometer-based ocean surface winds and in VARAMV due to the assimilation of atmospheric motion vectors. In Sect. 3.1.1, the fit of observations with analysis has shown considerable reduction of $\mathrm{O}-\mathrm{A}$ departures in wind, temperature and humidity parameters leading to improvement in initial condition due to the assimilation of observations. The assimilation of wind data over the ocean region around the cyclone in the cases VARPREP and VARPREP+RAD would lead to mass adjustments which would lead to wind and pressure changes. The meager changes in wind and pressure for VARRAD could be due to not using wind data in the assimilation. Among various experiments, VARPREP $+\mathrm{RAD}$ gives the most intensive cyclone vortex $\left(\Delta p \sim 5 \mathrm{hPa} ; \Delta u \sim 10 \mathrm{~m} \mathrm{~s}^{-1}\right)$ of all the experiments due to the assimilation of all types of wind data in addition to using temperature and humidity information from satellite radiances.

The impact of various observations on the analysis of wind, temperature and moisture for Phailin are analysed in the lower troposphere at $850 \mathrm{hPa}$ and upper troposphere at $200 \mathrm{hPa}$ (Figs. 5 and 6). The temperature and specific humidity in the lower troposphere at $850 \mathrm{hPa}$ from CTL and the corresponding differences for all assimilation experiments are presented in Fig. 5. In assimilation experiments, the pattern of temperature distribution at $850 \mathrm{hPa}$ level suggests the occurrence of a widespread cooling of the atmosphere in the lower levels by about $\sim 1 \mathrm{~K}$ in the region around the cyclone, in the north-west BOB and over the peninsular region, and warming by $\sim 1 \mathrm{~K}$ especially in an isolated region around the core of the cyclone. The temperature changes are more predominant in VARRAD and VARPREP+RAD rel- 

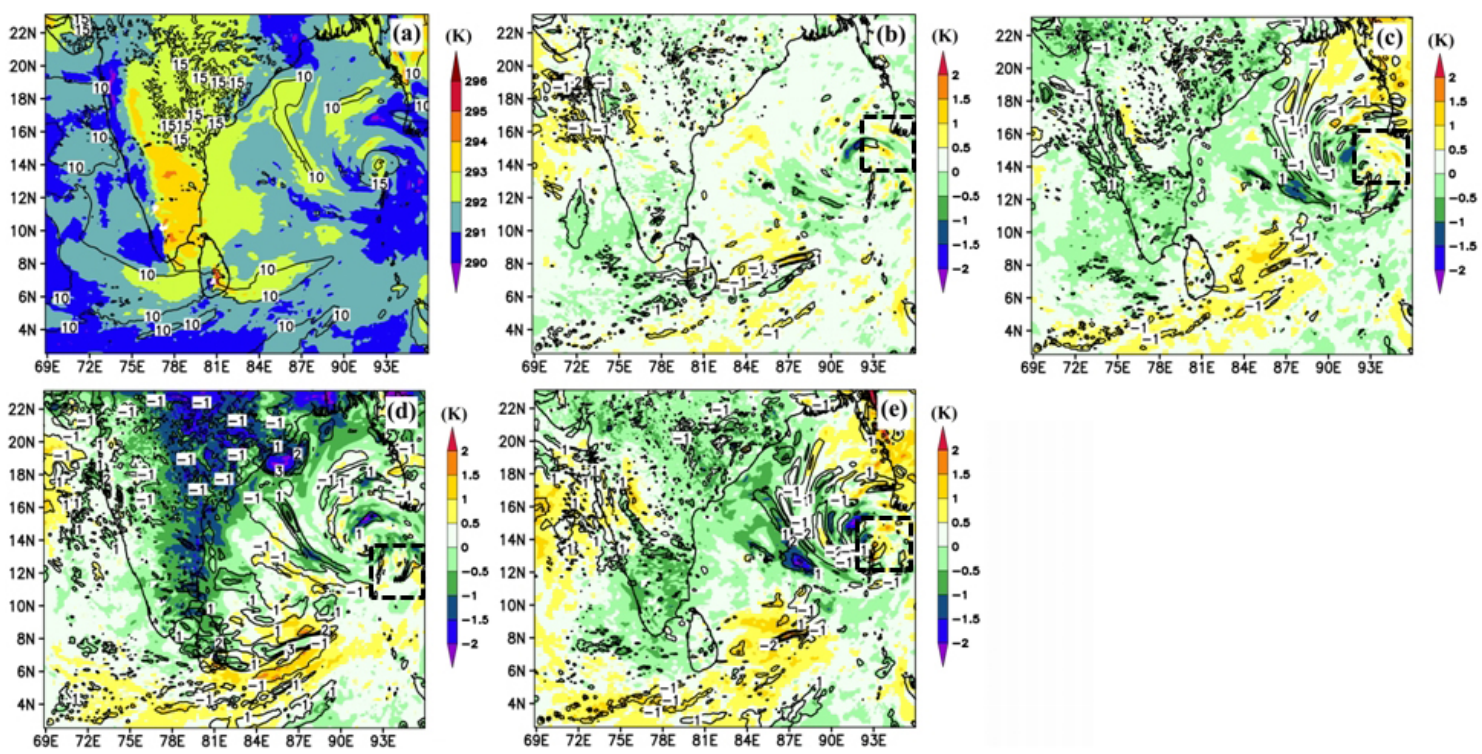

Figure 5. Spatial distribution of (a) initial temperature (shaded) and specific humidity (contours with interval of $1 \mathrm{~g} \mathrm{~kg}^{-1}$ ) at $850 \mathrm{hPa}$ in CTL and analysis difference (VAR - CTL) in (b) VARAMV, (c) VARPREP, (d) VARRAD and (e) VARPREP+RAD for Phailin at 12:00 UTC 9 October 2013.
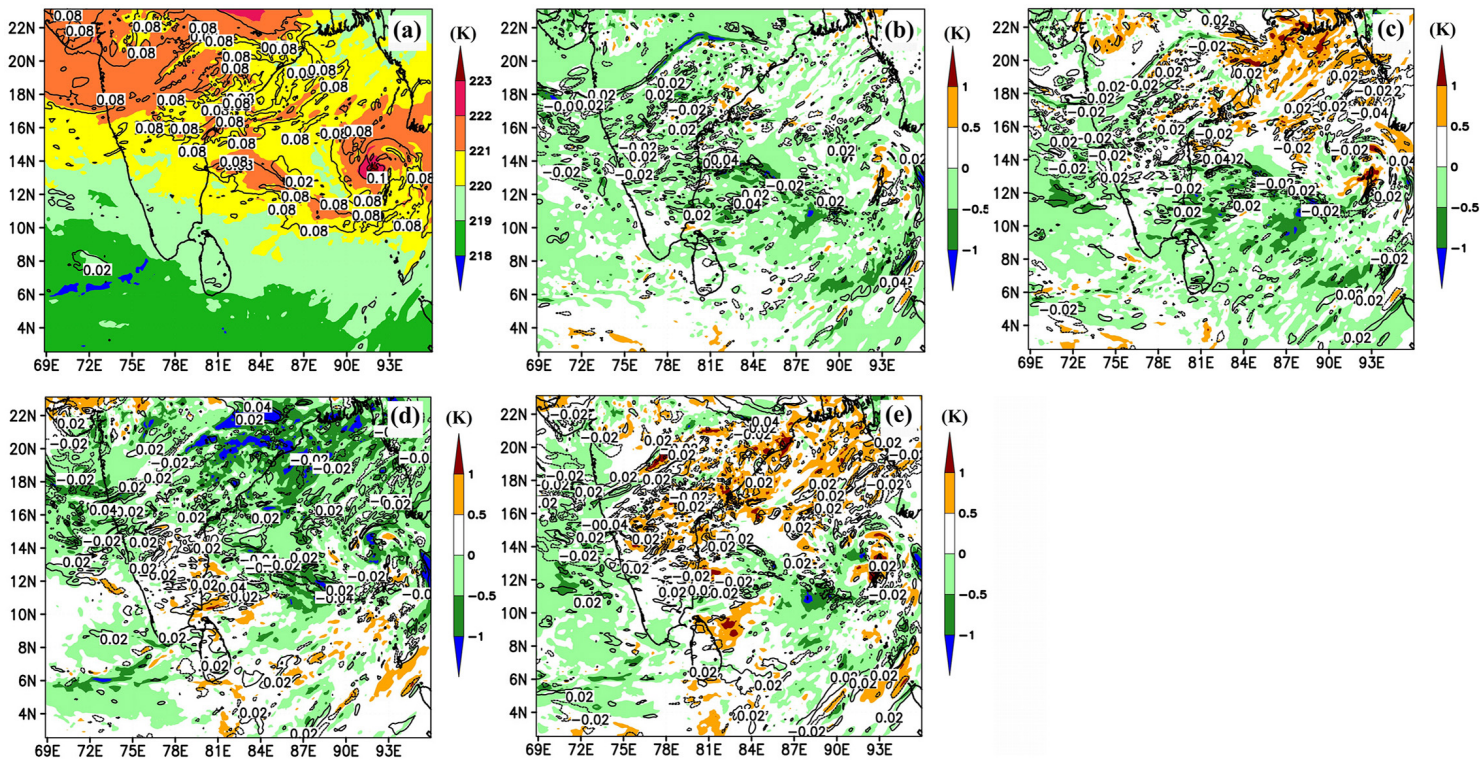

Figure 6. Spatial distribution of (a) initial temperature (shaded) and specific humidity (contours with interval $0.01 \mathrm{~g} \mathrm{~kg}^{-1}$ ) at $200 \mathrm{hPa}$ in CTL and analysis difference (VAR - CTL) in (b) VARAMV, (c) VARPREP, (d) VARRAD and (e) VARPREP+RAD for Phailin at 12:00 UTC 9 October 2013.

ative to VARPREP. The analysis differences show higher environmental cooling in the cyclone region with assimilation, and maximum cooling is found in VARRAD and VARPREP+RAD $(\Delta T \sim-2 \mathrm{~K})$, which also shows a warming of the central region by 1.0 and $1.5 \mathrm{~K}$ respectively. In $\mathrm{CTL}$, the core region of the cyclone has a higher specific humidity $\left(15 \mathrm{~g} \mathrm{~kg}^{-1}\right)$ compared to the large-scale environment. Humidity differences at $850 \mathrm{hPa}$ (Fig. 5) also suggest en- hancement in specific humidity of about $1-3 \mathrm{~g} \mathrm{~kg}^{-1}$ in the outer-core region of the cyclone in VARRAD, VARPREP and VARPREP+RAD experiments. The largest analysis increments in humidity $\left(\sim 3 \mathrm{~g} \mathrm{~kg}^{-1}\right)$ are found in VARRAD followed by VARPREP+RAD and VARPREP. In the upper troposphere at $200 \mathrm{hPa}$ level (Fig. 6), a warm core of $\sim 222-$ $224 \mathrm{~K}$ is seen in the region of the cyclone in all cases. However, temperature differences at $200 \mathrm{hPa}$ level indicate in- 

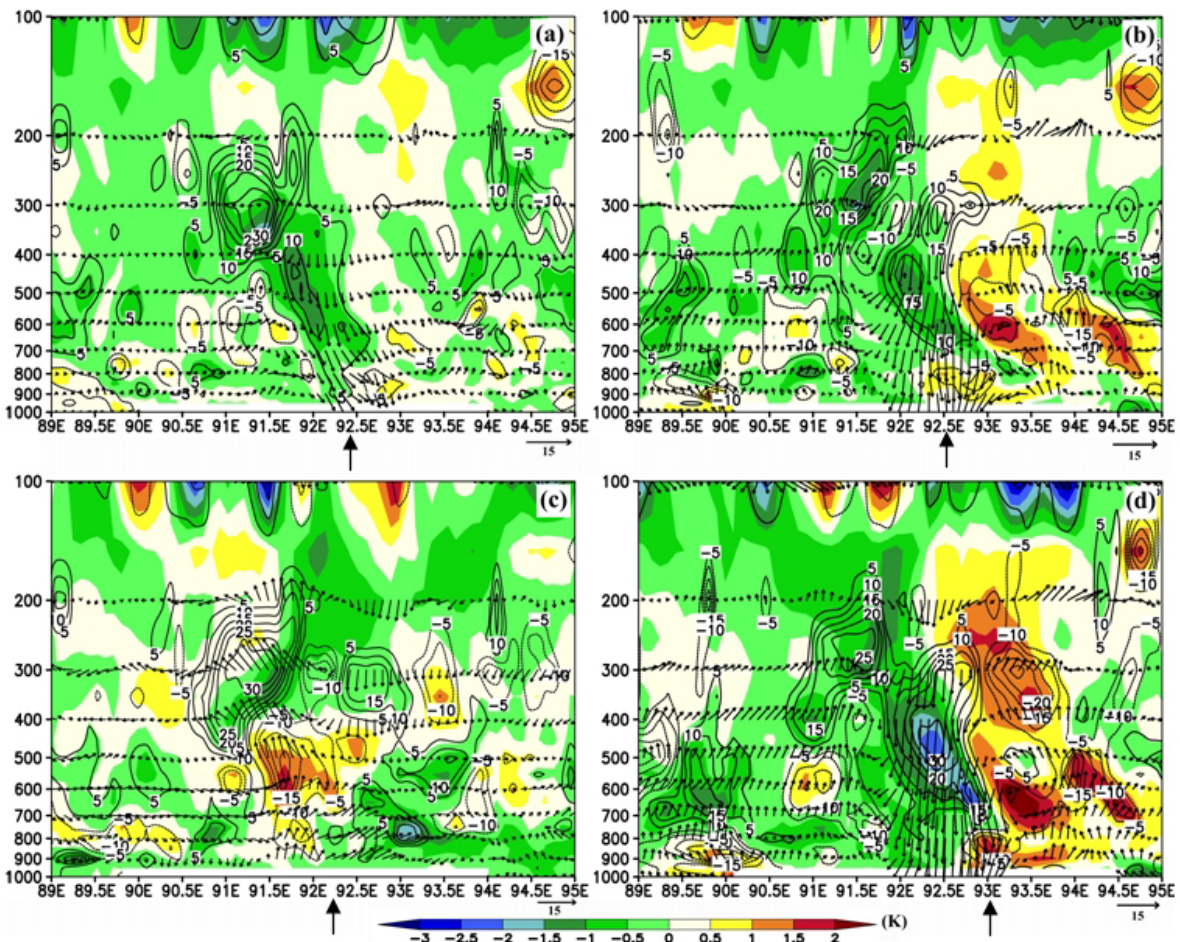

Figure 7. Vertical section of differences (VAR - CTL) in the distribution of temperature (shaded), humidity (contours; $\mathrm{g} \mathrm{kg}^{-1}$ ) and wind (vectors; $\mathrm{m} \mathrm{s}^{-1}$ ) patterns in (a) VARAMV, (b) VARPREP, (c) VARRAD and (d) VARPREP+RAD for Phailin at 12:00 UTC 9 October 2013. The arrow on the horizontal axis of each panel indicates the longitude position of cyclone for the corresponding experiment.

crease of temperature in the warm core by $\sim 0.5-1.5 \mathrm{~K}$ which covers wider areas in the VARPREP and VARPREP+RAD experiments. In all VAR experiments, the enhancement of humidity by $\sim 0.02 \mathrm{~g} \mathrm{~kg}^{-1}$ around the cyclone region is noted in the upper (200 hPa) atmosphere (Fig. 6).

The relatively large changes in temperature and humidity in VARRAD and VARPREP+RAD could be attributed to the assimilation of temperature and humidity profiles in these cases. Considerable reduction of errors in temperature and humidity parameters are found in Sect. 3.1.1 in VARPREP+RAD leading to improvement in the initial conditions. The assimilation of temperature/humidity data in these two cases (VARRAD and VARPREP+RAD) would lead to improvements in thermodynamics. The initial differences in temperature, relative humidity and tangential wind for Phailin are analysed in a vertical section extending from 1000 to $100 \mathrm{hPa}$ over a horizontal extension of $89-95^{\circ} \mathrm{E}$ around the cyclone along the latitudinal plane corresponding to the cyclone centre for each experiment (Fig. 7). The latitudinal planes are selected at $13.8087,13.6386,13.8087$ and $13.5647^{\circ} \mathrm{N}$ as per the location of the cyclone in VARAMV, VARPREP, VARRAD and VARPREP+RAD respectively. The analysis differences in the vertical plane reveal progressively stronger tangential circulation associated with the initial vortex in VARAMV, VARRAD, VARPREP and VARPREP+RAD relative to the
CTL experiment. In all the cases except VARAMV, warming of the atmosphere $(\sim 1.5-2.5 \mathrm{~K})$ from $700-300 \mathrm{hPa}$ layer is found. In VARPREP+RAD and VARPREP the warming is more prominent in the eastern side of the cyclone centre. In the western side, the temperature is colder than that of CTL in all experiments except VARRAD. The development of a convective cell (indicated by arrows) with warming $(\Delta T \sim 2.5 \mathrm{~K})$ in upper atmosphere and cooling $(\Delta T \sim-1 \mathrm{~K})$ in lower levels are seen particularly in experiments using radiance data (VARPREP+RAD and VARRAD). The stronger tangential winds in these experiments (VARPREP+RAD and VARRAD) enhance the low-level convergence leading to a stronger vortex. The above results suggest that the surface level vortex is stronger in VARPREP and VARPREP+RAD when all conventional and satellite observations are used in assimilation.

\subsubsection{Domain-wide analysis differences}

The analyses obtained from various data assimilation experiments are compared with the NCEP analysis used in CTL valid at 12:00 UTC 9 October 2013 by computing RMSE between the two as given below

$\mathrm{RMSE}^{\mathrm{VAR}}=\sqrt{\frac{1}{n}\left(\sum_{n}\left(\mathrm{Var}^{\mathrm{NCEP}}-\mathrm{Var}^{\mathrm{VAR}}\right)^{2}\right.}$, 

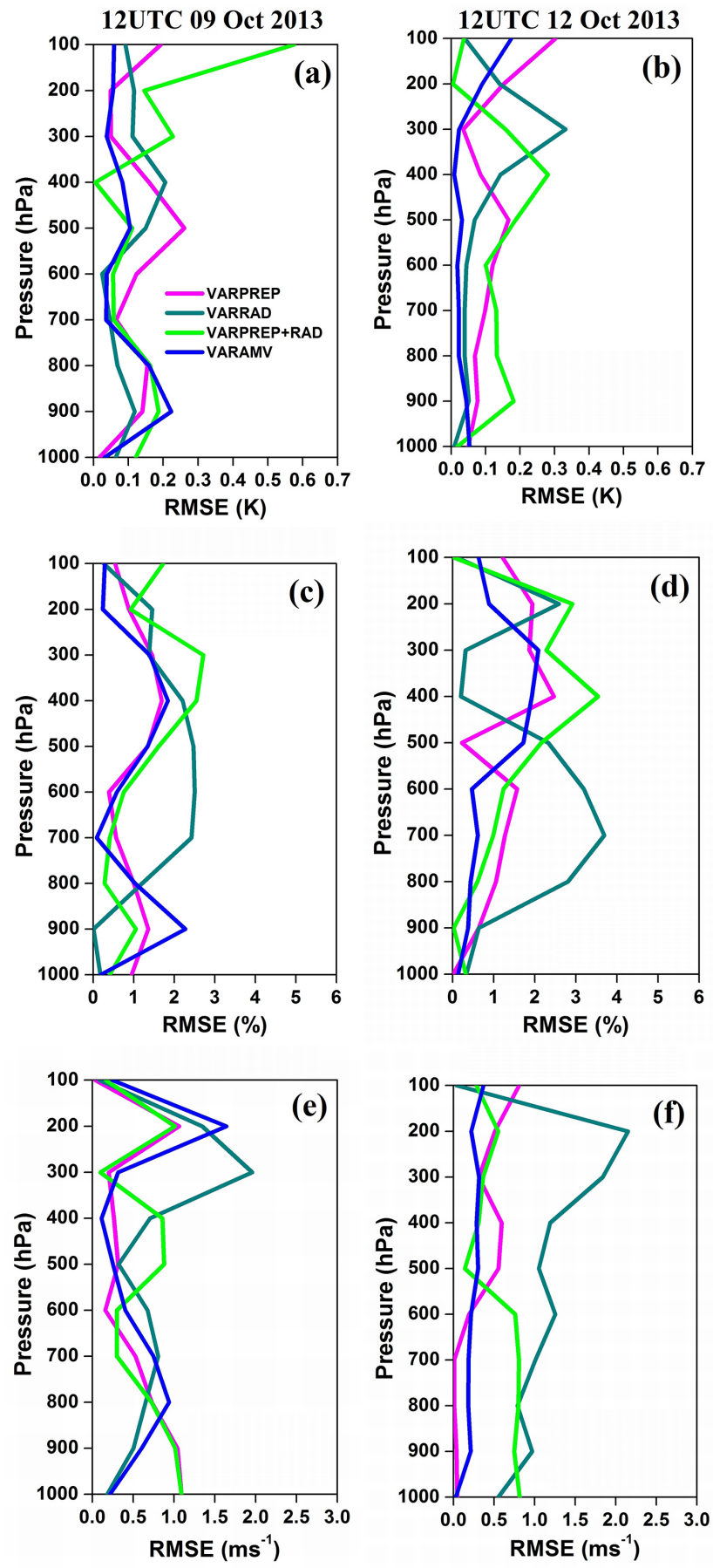

Figure 8. Vertical profile of domain-averaged RMSE for $(\mathbf{a}, \mathbf{b})$ temperature $(\mathrm{K}),(\mathbf{c}, \mathbf{d})$ relative humidity $(\%)$ and $(\mathbf{e}, \mathbf{f})$ wind speed $\left(\mathrm{m} \mathrm{s}^{-1}\right)$ relative to CTL. The left panels $(\mathbf{a}, \mathbf{c}, \mathbf{e})$ are differences at initial time for 12:00 UTC 9 October and right panels $(\mathbf{b}, \mathbf{d}, \mathbf{f})$ are differences for 3-day forecasts for 12:00 UTC 12 October.

where RMSEVAR is the root mean square error between NCEP (Var ${ }^{\mathrm{NCEP}}$ ) and 3D-Var (Var ${ }^{\mathrm{VAR}}$ ) analysis of temperature, moisture and wind. The vertical profile of domainaveraged (i.e. average is calculated over the inner domain)
RMSE between NCEP analysis and the analysis for temperature, moisture and wind from the 3D-Var experiments is shown in Fig. 8. The RMSE profiles from various 3DVar experiments show differences from the NCEP analysis for various parameters. The temperature analysis indicates increments of $0.175 \mathrm{~K}$ with the assimilation of PrepBUFR and AMSU radiances, $0.223 \mathrm{~K}$ with the assimilation of motion vectors, $0.135 \mathrm{~K}$ with the assimilation of the PrepBUFR data and $0.118 \mathrm{~K}$ with the assimilation of AMSU radiances in the lower atmosphere $(850-1000 \mathrm{hPa})$. The temperature increments are larger in the upper layers $500-100 \mathrm{hPa}$ in VARPREP and VARRAD and in the upper troposphere $(200-100 \mathrm{hPa})$ in VARPREP+RAD. The humidity increments are predominant (2-3\%) throughout the atmosphere in VARPREP+RAD and VARRAD. Also, it is found that the humidity distribution in VARPREP and VARAMV are similar in the $300-600 \mathrm{hPa}$ layer after second cycle of the assimilation. There are marginal wind increments of about $1 \mathrm{~m} \mathrm{~s}^{-1}$ in VARPREP and VARPREP+RAD in the lower atmosphere, about $0.8 \mathrm{~m} \mathrm{~s}^{-1}$ in VARAMV and VARRAD in the middle atmosphere and large wind increments in the upper atmosphere in VARAMV and VARRAD. Overall, the RMSE analysis suggests domain-wide increments in temperature, humidity and wind in 3D-Var experiments, with higher increments of temperature in VARAMV, VARPREP+RAD and VARPREP of humidity in VARRAD and VARPREP+RAD and of upper atmospheric winds in VARRAD and VARAMV. The VARPREP+RAD has brought out clear changes in all the parameters. The impact of differences or increments in the environmental parameters is analysed from the RMSE of model forecast parameters between CTL and 3D-Var experiments. The domainwide analysis increments are propagated with model integration. Vertical variation of domain-averaged RMSE between CTL and 3D-Var experiments (Fig. 8) shows large differences in VARPREP+RAD, VARPREP and VARRAD for temperature, VARRAD and VARPREP+RAD for humidity and VARPREP, VARRAD and VARPREP+RAD for winds at the end of $72 \mathrm{~h}$ of model integration over the CTL. The profiles on the right panels of Fig. 8 show clear decrease/increase from analysis time to 3-day forecast. The differences are discernible from $900 \mathrm{hPa}$ upwards for temperature with VARRAD and VARPREP+RAD, $850 \mathrm{hPa}$ upwards for humidity with VARRAD and $1000 \mathrm{hPa}$ upwards for winds with VARRAD and VARPREP+RAD. Also, a remarkable decrease in the RMSE of temperature in VARAMV in lower troposphere and in VARPREP+RAD above $300 \mathrm{hPa}$ and of wind speed in VARAMV and VARPREP are noticed. The impact of these domain-wide differences in temperature, humidity and wind on the evolution of the intensity and track parameters are analysed below from different experiments. 

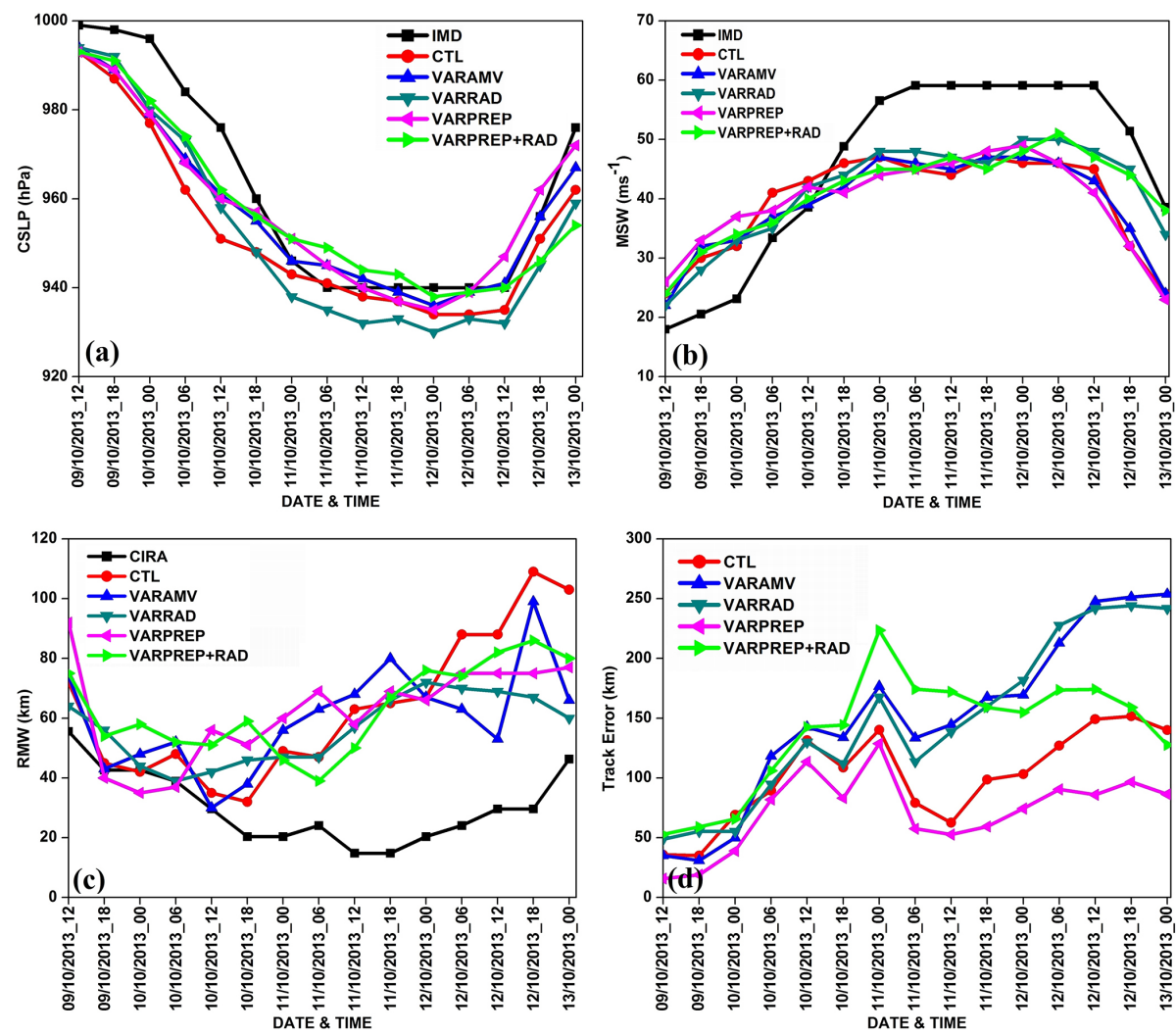

Figure 9. Time variation of (a) CSLP (hPa), (b) MSW $\left(\mathrm{m} \mathrm{s}^{-1}\right)$, (c) RMW $(\mathrm{km})$ and (d) vector track errors $(\mathrm{km})$ of Phailin in CTL and 3D-Var experiments (time in UTC). The CSLP and MSW of the operational IMD forecasts and RMW of CIRA data are also plotted.

\subsubsection{Intensity and track errors in CTL and VAR experiments}

The intensity of Phailin is analysed from the time evolution of CSLP and MSW (Fig. 9). In both CTL and assimilation experiments the CSLP is underestimated, MSW is overestimated up to cyclone stage, i.e. up to 12:00 UTC 10 October 2013, indicating overestimation of intensity.during the deepening/developing phase. In the peak intensification phase (12:00 UTC 11 October 2013 to 12:00 UTC 12 October 2013), though all simulations underestimated the winds compared to IMD data, the VARPREP, VARRAD and VARPREP+RAD have simulated stronger surface winds (by $5-10 \%$ ) compared to CTL. During this period, VARRAD, followed by CTL, shows an increased pressure drop with respect to IMD and VARAMV, whereas VARPREP and VARPREP+RAD simulated the CSLP with a smaller error compared to other experiments. The lowest CSLP and highest MSW during the peak intensification of Phailin are found in VARPREP+RAD (Fig. 9a, b). All the experiments show similar timing of deepening as in IMD data (about $30 \mathrm{~h}$ from 00:00 UTC 10 October 2013). The above results show that the experiments VARPREP and VARPREP+RAD produced 5-10\% smaller errors in CSLP and MSW over CTL and indicate a better simulation of storm intensity. As per the CIRA observations, the radius of maximum winds in the life cycle of the storm ranges from 15 to $55 \mathrm{~km}$ (Fig. 9c). The RMW simulated in all model experiments are similar to observations for the first $36 \mathrm{~h}$. Subsequently, they deviated from observations. The CTL shows large deviation from the CIRA observations with time indicating a larger cyclone size than observations. Comparable results are shown by VARRAD, which has $10-15 \%$ smaller deviation of RMW values from CIRA observations than other experiments.

The time series of errors in vector track positions for Phailin, from CTL and 3D-Var experiments, are presented in Fig. 9d. The simulated track is deviated to the northeast of the observed track and largest errors are simulated by VARRAD, VARPREP+RAD and VARAMV relative to the CTL. The initial track error varied as $20-50 \mathrm{~km}$ in all experiments. While the track errors progressively increased throughout the storm life cycle in VARAMV and VARRAD, the error increased initially until 00:00 UTC on 11 October and then decreased temporarily and then they increased again in CTL, VARPREP and VARPREP+RAD. Radiances and motion vectors seem to produce meager impacts on track predictions as seen in large track errors with VARRAD and VARAMV at almost all forecast times (Fig. 9d). The results suggest VARPREP produced the least track errors (10, 40, $135,60,80 \mathrm{~km}$ at $12,24,48,72$ and $96 \mathrm{~h}$ ) followed by CTL, 

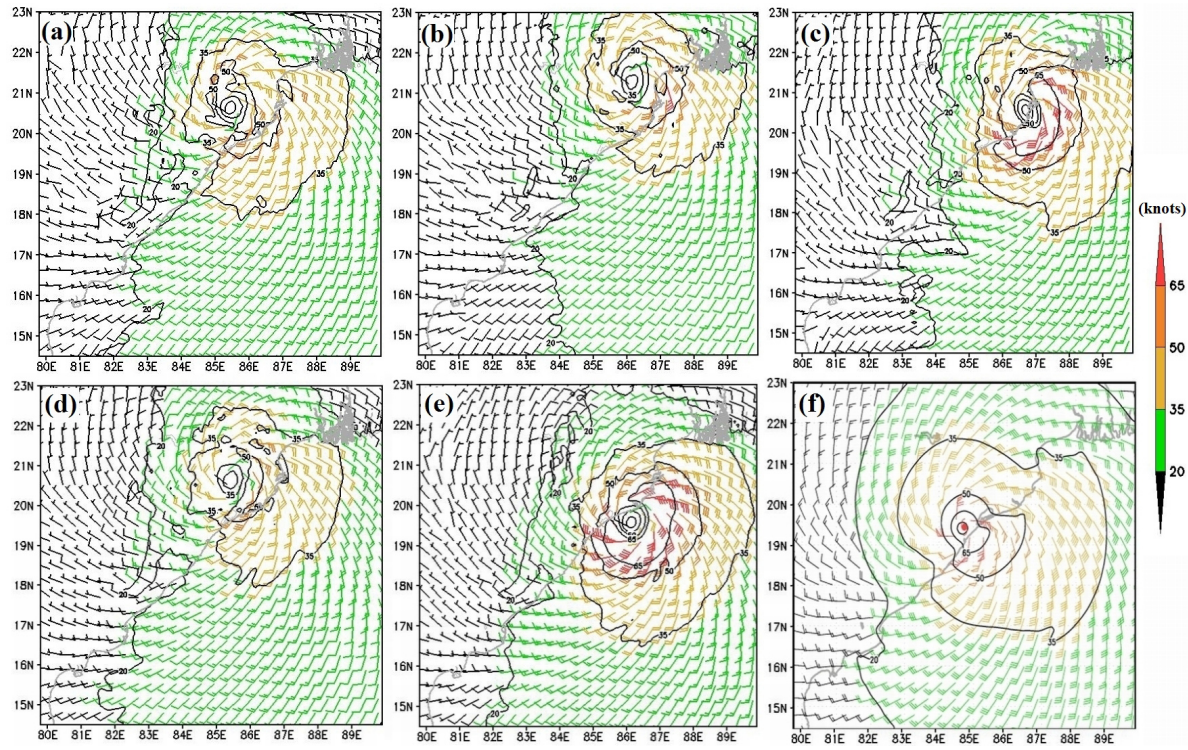

Figure 10. Comparison of wind flow around Phailin at 18:00 UTC 12 October 2013 from experiments (a) CTL, (b) VARAMV, (c) VARRAD, (d) VARPREP and (e) VARPREP+RAD with (f) CIRA multi-satellite observations. The contours represent the strength of the horizontal winds in knots.

VARPREP+RAD, VARRAD and VARAMV. The track errors are reduced by $10-40 \%$ from $24-84 \mathrm{~h}$ of simulation in VARPREP. The landfall position errors are also lowest in VARPREP $(\sim 80 \mathrm{~km})$, followed by VARPREP+RAD and CTL $(\sim 150 \mathrm{~km})$. As per IMD reports, the landfall occurred at 16:00 UTC of 12 October. The VARPREP simulates an early landfall, $4 \mathrm{~h}$ before the actual landfall. Though a slight improvement in intensity predictions is found using assimilation of radiances and motion vectors, their impact on the track is meager. The negative impact of radiance and motion vector observations on track positions could be due to the poor area coverage of the above data sets for Phailin.

\subsubsection{Structure prediction}

\section{Surface wind field}

The surface wind flow pattern simulated by different experiments is compared with corresponding CIRA winds (Fig. 10) for the Phailin case just after landfall (at 18:00 UTC 12 October 2013). The CIRA wind data indicates an intense cyclonic storm with maximum winds of up to 80 knots $\left(\sim 41 \mathrm{~m} \mathrm{~s}^{-1}\right)$ located along the coast near Gopalpur (near $19.26^{\circ} \mathrm{N}, 84.9^{\circ} \mathrm{E}$ ) in Orissa where the storm had crossed the land. The corresponding wind field from different experiments shows that the simulated cyclone is less intensive in the CTL and 3D-Var experiments (VARAMV, VARPREP) and the distribution of the wind field from VARRAD and VARPREP + RAD agrees well with CIRA data. The strongest winds are mainly distributed in the forward right sector, and are well simulated in the experiments VARRAD, VARPREP and VARPREP+RAD. The simulated storm is located about
$80 \mathrm{~km}$ north, $100 \mathrm{~km}$ north-north-east, $125 \mathrm{~km}$ north-east, $50 \mathrm{~km}$ north and $50 \mathrm{~km}$ east of the actual storm in the experiments CTL, VARAMV, VARRAD, VARPREP and VARPREP+RAD respectively. The location and intensity of the cyclone are best simulated in the VARPREP+RAD experiment.

\section{Reflectivity}

The maximum reflectivity from ARW simulations is compared with DWR reflectivity image of IMD, Visakhapatnam (Fig. 11), corresponding to the highest intensification stage of the storm, i.e. 12:00 UTC 12 October 2013. The DWR observation covers an area of $14.250-21^{\circ} \mathrm{N}, 80-86^{\circ} \mathrm{E}$. Since the model-simulated reflectivity covers a wider area ( $14.25-$ $22^{\circ} \mathrm{N}, 80-88^{\circ} \mathrm{E}$ ), the same has been chosen for comparison with the observation. The actual landfall position is shown by the cyclone symbol in maroon. The actual landfall occurred at 16:00 UTC of 12 October near $19.26^{\circ} \mathrm{N}$, $84.9^{\circ} \mathrm{E}$. The early landfall of the cyclone in the experiments CTL, VARAMV, VARPREP could be identified in this figure. Since reflectivity indicates the areas of deep convection, distribution of the clouds and areas of intense rainfall, it can be used as an indicator of the strength of cyclone. The reflectivity from all simulations and DWR data shows well-organized convective cloud bands around the storm in a comma structure indicating a severe cyclonic storm. The DWR reflectivity data indicates a less intense storm than the simulated cyclone in various experiments supporting our previous discussions. While all simulations indicate a circular symmetry of the cloud structure, VARPREP+RAD better simulated the structure with a well-defined central eye re- 

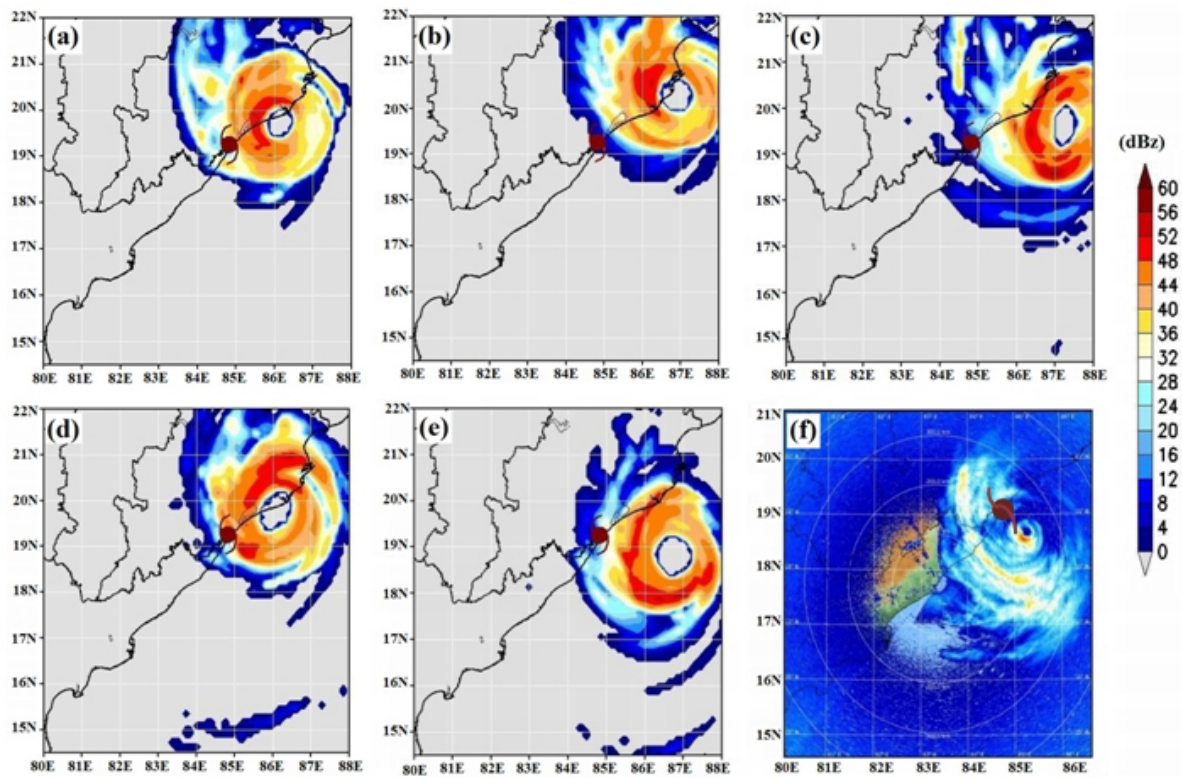

Figure 11. Comparison of simulated maximum reflectivity (dBZ) of hydrometeors for Phailin at 12:00 UTC 12 October 2013 from (a) CTL, (b) VARAMV, (c) VARRAD, (d) VARPREP, (e) VARPREP+RAD and (f) IMD DWR image. The cyclone symbol in maroon indicates the actual landfall of the cyclone.
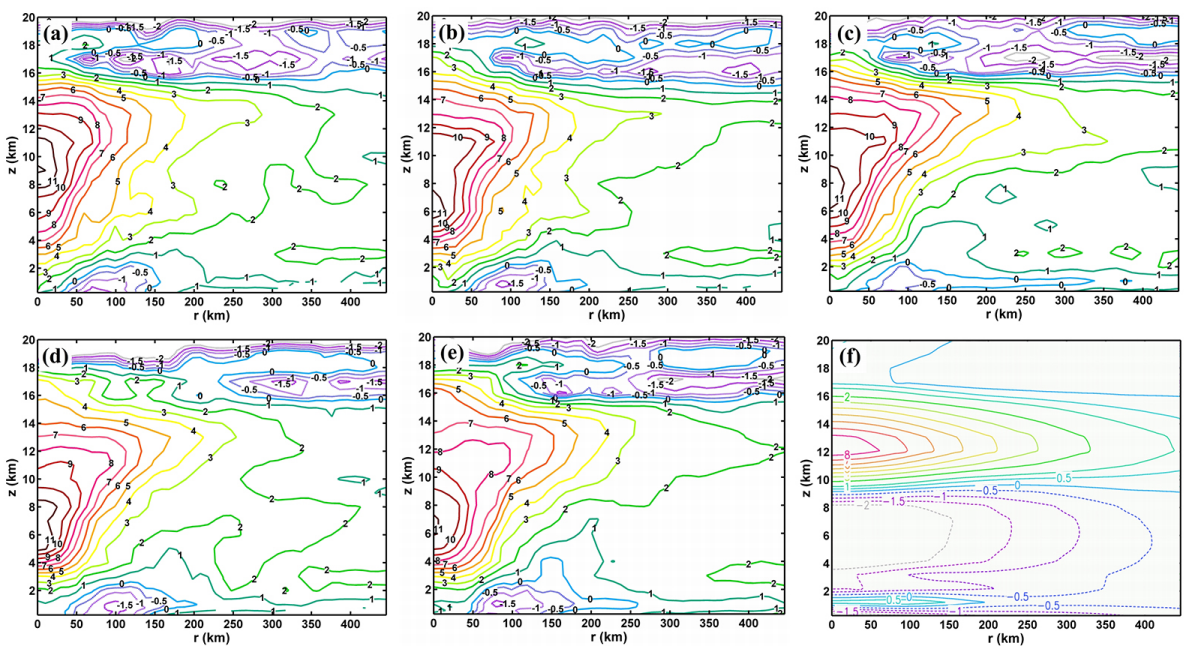

Figure 12. Depiction of the azimuthally averaged radius-height cross-section of temperature anomaly (K) for Phailin from experiments (a) CTL, (b) VARAMV, (c) VARRAD, (d) VARPREP, (e) VARPREP+RAD and (f) CIRA multi-satellite data at mature stage of the cyclone corresponding to 06:00 UTC 12 October 2013. Here, $r$ is the radius from the centre of the cyclone and $z$ is the height.

gion and with eastward and northward extension of cloud bands as in the DWR data. The asymmetric distribution of rain/cloud bands, the spread of rainfall activity in the northern and south-western land areas and southern ocean sectors of the cyclone are well simulated in VARPREP+RAD.

\section{Vertical temperature structure}

Cyclones are associated with warming in the upper troposphere due to adiabatic warming by the subsidence of air in the eye of the cyclone. At the lower levels, cooling takes place due to evaporation of precipitation and downdrafts. Warming is measured by temperature anomaly which is the difference between the temperature of the large-scale environment and the core region of cyclone. The radius-height cross-section of azimuthally averaged temperature anomaly for Phailin at its mature stage (06:00 UTC on 12 October 2013) from CTL and 3D-Var simulations, along with CIRA observations, is presented in Fig. 12. A temperature anomaly due to cyclone is computed as the difference in temperature 

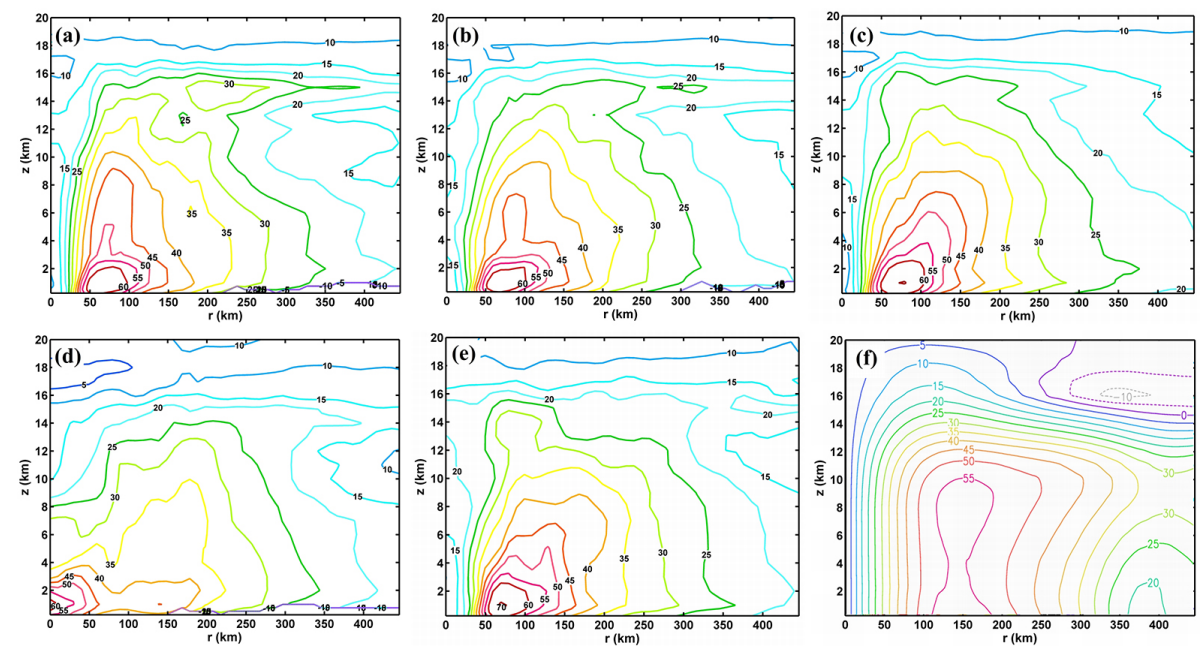

Figure 13. Depiction of the azimuthally averaged radius-height cross-section of tangential winds for Phailin from experiments (a) CTL, (b) VARAMV, (c) VARRAD, (d) VARPREP, (e) VARPREP+RAD and (f) CIRA multi-satellite data at mature stage of the cyclone corresponding to 06:00 UTC 12 October 2013. Here, $r$ is the radius from the centre of the cyclone and $z$ is the height.

at the intense stage of the cyclone at each grid point and at each level in the model from the temperature before the formation of the cyclone. All the 3D-Var experiments simulated higher warming than CIRA data. CIRA data indicates the convective warming is confined to $8-16 \mathrm{~km}$ with a maximum warming of $8 \mathrm{~K}$ at about $12 \mathrm{~km}$, suggesting the formation of deep convective layer due to the cyclone. CIRA data also indicates a cooling of -0.5 to $-2.0 \mathrm{~K}$ in the $0-2 \mathrm{~km}$ layer of lower troposphere. While CIRA data shows cooling in the lower regions (vertically up to $8 \mathrm{~km}$ ), all the simulations indicate cooling from 50 to $150 \mathrm{~km}$ from the centre of the cyclone with a vertical extension up to $2 \mathrm{~km}$. However the upper-level warming in the simulations matches with the CIRA data. The CTL, VARAMV and VARRAD (Fig. $12 \mathrm{a}, \mathrm{b}$ and c) indicate overestimation of core warming and also simulate high vertical velocities of the order of $90-180 \mathrm{~cm} \mathrm{~s}^{-1}$ in the core region (not shown). The experiment VARPREP shows more vertical warming $(\sim 11 \mathrm{~K})$ at the $5-8.5 \mathrm{~km}$ layer confined to a region of $0-25 \mathrm{~km}$ from the centre of the cyclone, whereas in VARPREP+RAD the warm core is seen in the $6-7.5 \mathrm{~km}$ layer and horizontally in the region $0-15 \mathrm{~km}$ from the cyclone centre. Thus, it is evident that among all the experiments, VARPREP+RAD simulated the horizontal and vertical extension of upper-level warming and lower-level cooling around the core region better in comparison with CIRA data.

The radius-height cross-section of azimuthally averaged tangential winds around cyclone from various experiments for the Phailin case at its mature stage (06:00 UTC on 12 October 2013) along with CIRA observations are presented in Fig. 13. Observations indicate maximum winds of $>55 \mathrm{~m} \mathrm{~s}^{-1}$ prevailing from the surface up to $10 \mathrm{~km}$ and thereupon winds reduced gradually upwards. While the CIRA data shows the maximum winds to be confined in a range of 110 to $190 \mathrm{~km}$, all the experiments except VARPREP show prevalence of maximum winds in a radius of $50-100 \mathrm{~km}$ from the eye of the storm. Maximum tangential winds simulated in various experiments are of the order of $60-70 \mathrm{~m} \mathrm{~s}^{-1}$ around the cyclone, indicating overestimation of the strength of the cyclone as noted in the previous discussions. However, the azimuthal distribution of tangential winds is simulated differently in different experiments. Though all the simulations bring out the vertical variation of horizontal winds, the horizontal extension of maximum winds is better simulated by the 3D-Var experiments VARPREP, VARRAD and VARPREP+RAD.

\section{Rainfall}

The spatial distribution of simulated $24 \mathrm{~h}$ cumulative rainfall for Phailin ending on 00:00 UTC 13 October 2013 from different experiments is compared with TRMM 3B42 rainfall (http://mirador.gsfc.nasa.gov/collections/TRMM_3B42_ daily_007.shtml) estimates (Fig. 14). The cyclone positions on 00:00 UTC 12 October and 00:00 UTC 13 October are indicated by cyclone symbols in red and the direction of movement is shown by an arrow (sky blue) in each panel. The distribution and location of maximum rainfall slightly varied in various experiments according to the simulated landfall positions in each case. The TRMM data show a near circular distribution of rainfall but slightly elongated in the north-south direction. It shows a heavy rainfall band (22$24 \mathrm{~cm} \mathrm{day}^{-1}$ ) at the border of northern Andhra Pradesh and southern Orissa near Paradeep, with radially decreasing rainfall away from the storm centre, and with outer rainfall bands extending over central and southern BOB. This suggests that the rainfall over land portion was mainly distributed in Orissa, northern coastal Andhra Pradesh and southern parts of West Bengal and Bihar. The assimilation of radiance and 

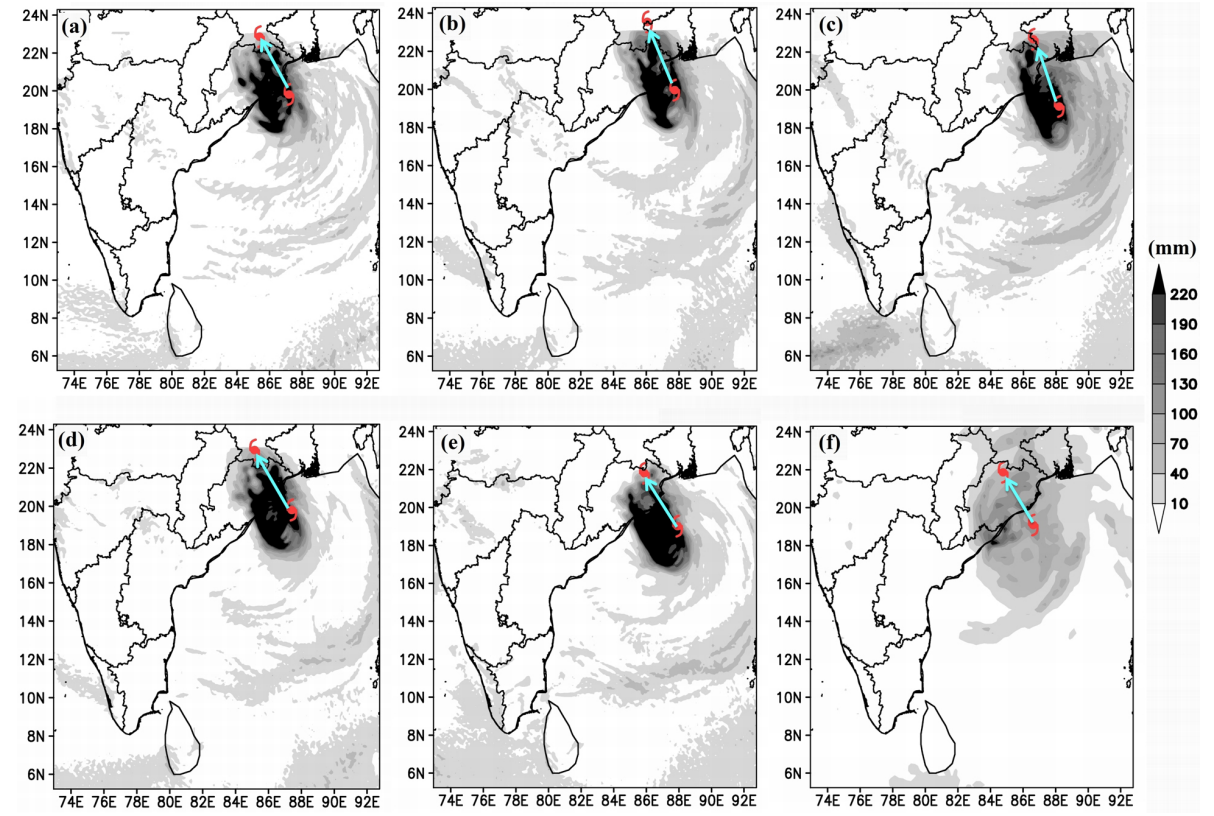

Figure 14. Comparison of simulated cumulative $24 \mathrm{~h}$ rainfall for Phailin on 12 October 2013 from (a) CTL, (b) VARAMV, (c) VARRAD, (d) VARPREP, (e) VARPREP+RAD and (f) TRMM observation. The cyclone symbols in red indicates the initial and final position of the cyclone during this day (from 00:00 UTC 12 October to 00:00 UTC 13 October 2013) and the arrow (sky blue) shows the direction of movement of the cyclone.

motion vector observations improved the rainfall simulation in terms of distribution. In all the experiments, the rainfall is overestimated by about $40 \%$ in the core region of the cyclone. The 3D-Var experiment VARRAD, followed by VARPREP+RAD, simulated the rainfall characteristics of quantity, location and distribution in the outer-core region in better agreement with TRMM data. The maximum convective available potential energy (CAPE) values averaged for a $3 \times 3^{\circ}$ area around Phailin are calculated. The CAPE values are 1490.8, 1493.5, 1511.6, 1504.7, $1576.7 \mathrm{~J} \mathrm{~kg}^{-1}$ in CTL, VARAMV, VARRAD, VARPREP and VARPREP+RAD respectively at the end of $36 \mathrm{~h}$ of model integration. The CAPE values indicate stronger convective conditions simulated with VARPREP+RAD followed by VARRAD and VARPREP. The same trends in CAPE are maintained throughout the simulations. The improvements in rainfall predication in VARRAD and VARPREP+RAD could be due to stronger convective conditions associated with changes in model thermodynamics through domain-wide temperature and humidity increments (Fig. 8).

\subsection{Results of track and intensity prediction for all cyclones}

\subsubsection{Tracks of the simulated storms}

Among various predicted parameters, the movement of the cyclone (or track) is more important as the final landfall position is often given more attention than the storm intensity in disaster mitigation. The predicted tracks from control and assimilation experiments, along with best track data from IMD, in different cyclone cases are presented in Fig. 15. The simulated tracks are seen to be closer to IMD best tracks in the experiments VARPREP for Phailin, Laila and Madi; VARAMV for Thane, Khaimuk and Lehar; and VARPREP+RAD for Nilam and Jal. The track simulations indicate different impacts from the assimilation of different observation sources. It has been noted that VARRAD produced a negative impact on track predictions in many cases and the errors are larger than in the CTL experiments.

\subsubsection{Quantitative track and intensity errors}

The general uncertainty in cyclone numerical predictions can be analysed from a statistical error distribution of parameters like track positions, MSW and CSLP considering a large number of cyclones. In this study, the errors in the model predictions are calculated using IMD best track data as a reference. Mean error (ME) and standard deviation (SD) are computed for track positions, MSW, CSLP and RMW for all eight cyclones (Table 2). The ME is the average of errors of all cyclones at a given forecast time. The SD represents the error distribution around the mean error. Model performance can be assessed from the error scatter with respect to time using ME + SD and ME - SD as thresholds. The time series of percentage improvement in predictions for various parameters are shown in Fig. 16. The errors in track positions from CTL indicate a wide scatter, and maximum errors are 


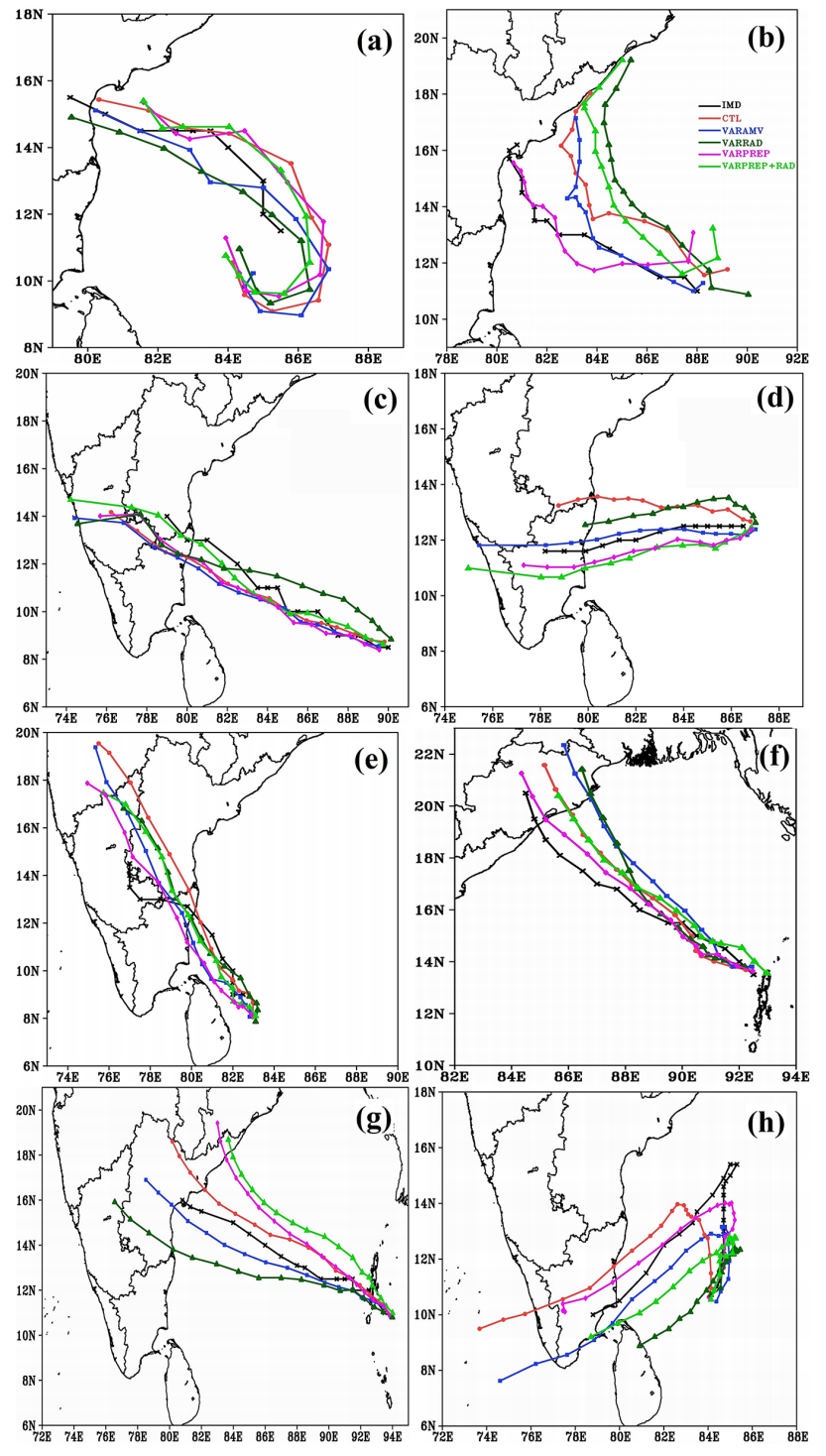

Figure 15. Simulated vector track positions along with IMD best track from CTL and 3D-Var experiments for eight tropical cyclones over the BOB (a) Khaimuk, (b) Laila, (c) Jal, (d) Thane, (e) Nilam, (f) Phailin, (g) Lehar and (h) Madi.

associated with Nilam $(584.9 \mathrm{~km})$ and minimum with Lehar $(12.6 \mathrm{~km})$. In all experiments track errors increased continuously. Track errors in CTL run during the first $18 \mathrm{~h}$ of integration are in the range of the error threshold except Khaimuk. From 18 to $48 \mathrm{~h}$ error build-up is observed. It has been found that during the first 2 days of simulation the model gives better track prediction in CTL for the cyclones Nilam, Phailin and Thane. Secondly the control simulations for the cyclones Phailin and Jal produce lower errors than the mean error of the entire sample of selected cyclones. The mean track error of all CTL ranges from 99 to $319 \mathrm{~km}$ for 24 to $96 \mathrm{~h}$ forecasts. A drastic reduction in track errors can be found in VARAMV and VARPREP (Fig. 16a) with a small scatter of errors about
Table 2. Mean error (ME) and standard deviation (SD) in vector track position, CSLP, MSW and the radius of maximum winds (RMW) in different experiments for all eight selected tropical cyclones.

\begin{tabular}{|c|c|c|c|c|c|c|c|c|}
\hline \multirow[t]{2}{*}{$\begin{array}{l}\text { Forecast } \\
\text { period } \\
\text { (h) }\end{array}$} & \multicolumn{2}{|c|}{$\begin{array}{c}\text { Track } \\
\text { error } \\
\text { position } \\
(\mathrm{km})\end{array}$} & \multicolumn{2}{|c|}{$\begin{array}{c}\text { Error in } \\
\text { central sea } \\
\text { level } \\
\text { pressure }(\mathrm{hPa})\end{array}$} & \multicolumn{2}{|c|}{$\begin{array}{l}\text { Error in } \\
\text { max. } \\
\text { winds } \\
\left(\mathrm{ms}^{-1}\right)\end{array}$} & \multicolumn{2}{|c|}{$\begin{array}{l}\text { Error in } \\
\text { radius of } \\
\text { max. winds } \\
(\mathrm{km})\end{array}$} \\
\hline & ME & SD & $\mathrm{ME}$ & SD & $\mathrm{ME}$ & SD & ME & SD \\
\hline \multicolumn{9}{|c|}{ CTL } \\
\hline 24 & 99.1 & 99.8 & 13.5 & 10.5 & -9.8 & 7.8 & -2.1 & 19.3 \\
\hline 48 & 152.1 & 88.2 & 14.0 & 14.5 & -6.7 & 10.8 & -14.4 & 21.9 \\
\hline 72 & 246.7 & 112.9 & 12.8 & 14.6 & -5.6 & 11.2 & -7.9 & 23.2 \\
\hline 96 & 319.0 & 106.8 & 9.6 & 4.4 & -3.1 & 10.1 & -24.5 & 44.4 \\
\hline \multicolumn{9}{|c|}{ VARAMV } \\
\hline 24 & 93.5 & 93.9 & 12.0 & 10.4 & -10.2 & 7.8 & -0.4 & 26.9 \\
\hline 48 & 129.8 & 91.9 & 9.5 & 12.8 & -6.9 & 10.1 & -8.0 & 25.2 \\
\hline 72 & 202.4 & 87.6 & 7.1 & 15.0 & 0.1 & 11.5 & -10.6 & 25.8 \\
\hline 96 & 322.6 & 117.4 & 8.0 & 7.9 & -2.1 & 9.5 & 4.1 & 37.7 \\
\hline \multicolumn{9}{|c|}{ VARPREP } \\
\hline 24 & 77.8 & 76.1 & 10.3 & 8.4 & -10.8 & 7.5 & 2.6 & 22.2 \\
\hline 48 & 128.7 & 92.3 & 5.8 & 11.7 & -3.9 & 9.8 & -16.8 & 32.7 \\
\hline 72 & 165.6 & 84.9 & 4.8 & 14.2 & 0.2 & 10.2 & -37.9 & 64.7 \\
\hline 96 & 209.6 & 131.7 & 9.0 & 12.9 & -2.3 & 10.7 & -21.9 & 39.6 \\
\hline \multicolumn{9}{|c|}{ VARRAD } \\
\hline 24 & 134.4 & 87.6 & 12.4 & 6.6 & -9.6 & 5.2 & 5.7 & 12.0 \\
\hline 48 & 184.3 & 100.8 & 12.4 & 14.7 & -6.3 & 10.8 & -4.8 & 14.1 \\
\hline 72 & 257.3 & 106.6 & 5.9 & 15.8 & -3.6 & 10.3 & -27.0 & 59.7 \\
\hline 96 & 413.6 & 140.9 & 11.2 & 5.8 & -4.5 & 6.8 & 21.7 & 34.3 \\
\hline \multicolumn{9}{|c|}{ VARPREP+RAD } \\
\hline 24 & 95.6 & 69.5 & 10.1 & 7.5 & -9.2 & 7.2 & -2.9 & 27.7 \\
\hline 48 & 178 & 99.3 & 6.8 & 14.8 & -3.2 & 10.3 & -9.3 & 22.4 \\
\hline 72 & 244.7 & 87.7 & 6.4 & 17.3 & -0.6 & 13 & -56.8 & 58.8 \\
\hline 96 & 361.3 & 193 & 17.8 & 12.2 & -8.8 & 5.9 & 19.7 & 51.0 \\
\hline
\end{tabular}

the mean from $24 \mathrm{~h}$ of integration. The VARPREP produced the lowest track errors (78-210 km for 24-96 h forecasts) which are considerably lower than the mean track errors obtained in our earlier study (Srinivas et al., 2013) using simple downscaling approach for 21 cyclones. Except for Khaimuk, track errors were reduced with data assimilation for all other cyclone cases considered. An improvement of 15.4-34.3\% is found in track errors with VARPREP for 24-96 $\mathrm{h}$ forecasts over control experiments (Fig. 16). This is a very encouraging result for operational track predictions using WRF over the NIO region given the uncertainties in vortex specification. The experiment VARPREP+RAD deteriorated the track predictions with errors amplification.

For the majority of the cyclones the error in central pressure (IMD estimate less the simulated CSLP) is positive, suggesting an underestimation of central pressure thereby simulating stronger storms. The ME for CSLP in CTL ranges from 9.6 to $14.0 \mathrm{hPa}$ for $24-96 \mathrm{~h}$ forecasts (Table 2). Based on the CSLP simulation, Nilam and Madi are the best-simulated cyclones and Thane and Laila are simulated very poorly in CTL experiments. The experi- 

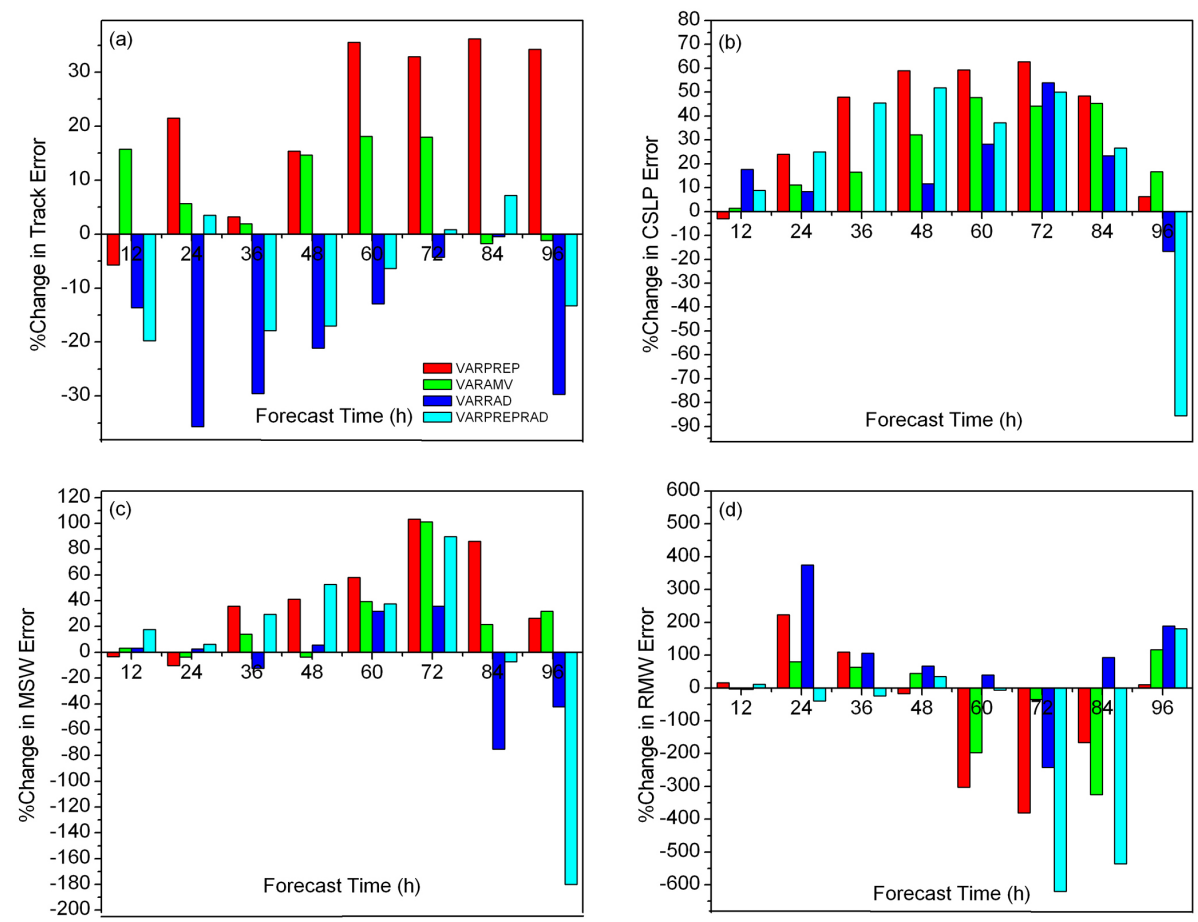

Figure 16. Error change in (a) track positions, (b) CSLP, (c) MSW and (d) RMW in 3D-Var experiments over control runs for all eight selected tropical cyclones. Positive values indicate improvement in simulation, i.e. errors are less with respect to CTL.

ment VARPREP produced large improvements in CSLP followed by VARPREP+RAD and VARRAD up to 72 forecast hours. The mean CSLP error in VARPREP ranges from 4.8 to $10.3 \mathrm{hPa}$ showing an improvement of $6-63 \%$ for $24-$ $96 \mathrm{~h}$ forecasts. This indicates assimilation of PrepBUFR data along with satellite-derived radiance observations provide best intensity estimates through the life cycle of the storms.

The error in the MSW indicates that the ME (IMD estimate less the model value) of the selected cyclones is negative, indicating that the model tendency to simulate stronger winds than observations and hence more intense cyclones. Based on the error in MSW, the intensity is better simulated in the cases of Nilam, Khaimuk, Lehar and Laila. The cyclone $\mathrm{Jal}$ is poorly simulated up to a forecast range of $42 \mathrm{~h}$, afterwards the winds are more realistically simulated. The simulation VARPREP produced large improvements in MSW followed by VARAMV, VARPREP+RAD and VARRAD. The mean wind errors in VARPREP vary from 0.2 to $-10.8 \mathrm{~m} \mathrm{~s}^{-1}$ leading to improvements of $26-103 \%$ for $24-96 \mathrm{~h}$ forecasts. Though CSLP and wind errors in VARPREP+RAD are relatively small up to $72 \mathrm{~h}$ compared to VARPREP, the former shows relatively large errors from $72 \mathrm{~h}$ onwards, indicating rapid and unrealistic weakening during landfall. The RMW gives a measure of the size of the cyclone. The average error found in RMW for all eight selected tropical cyclones indicates that almost all the 3D-Var experiments overestimate the size of the cyclone. Of all simulations, VARRAD produced the least RMW errors, i.e. $-27.0-21.7 \mathrm{~km}$ corre- sponding to 24-96h forecasts (Fig. 16). The time series of average errors of all eight cyclones clearly demonstrate that the assimilation of most commonly available observations in ARW model produces significant improvements in both cyclone track and intensity predictions.

The landfall errors of cyclones from different experiments are presented in Table 3. It has been found that the landfall position and timing errors for most cyclones are minimal in the VARPREP followed by VARPREP+RAD and maximum errors are noted with CTL followed by VARRAD and VARAMV. Landfall position errors are maximum for Madi, Phailin, Laila and Khaimuk in VARPREP+RAD, and CTL exhibited the maximum landfall position errors for Thane. The mean landfall position error is about $128.44 \mathrm{~km}$ from VARPREP and $183.51 \mathrm{~km}$ from VARRAD. The mean landfall time error (Table 3 ) is about $-4 \mathrm{~h}$ from VARRAD and $-9.3 \mathrm{~h}$ from CTL which indicate an early strike of the cyclones at the coast in simulations. Along-track deviation is the main factor in simulated landfall errors. Based on mean errors, VARPREP is seen to be the best simulation among the five experiments with mean landfall position error of $128.44 \mathrm{~km}$ and landfall time error of $-7.6 \mathrm{~h}$. As far as rainfall prediction is concerned, considering all eight tropical cyclones, rainfall is better simulated in VARAMV, followed by VARPREP, with relatively higher correlations and lower RMSE (Table 4). The mean error in rainfall has been calculated from the area-averaged rainfall deviations from TRMM 
Table 3. Errors in landfall position and landfall timing from various experiments. The negative time errors indicate early landfall and positive errors show late landfall.

\begin{tabular}{|c|c|c|c|c|c|c|c|c|c|c|}
\hline \multirow[b]{2}{*}{$\begin{array}{l}\text { Name of } \\
\text { Cyclone }\end{array}$} & \multicolumn{5}{|c|}{ Error in landfall position $(\mathrm{km})$} & \multicolumn{5}{|c|}{ Error in time of landfall (h) } \\
\hline & CTL & VARPREP & VARAMV & VARRAD & $\begin{array}{r}\text { VARPREP } \\
+ \text { RAD }\end{array}$ & CTL & VARPREP & VARAMV & VARRAD & $\begin{array}{r}\text { VARPREP } \\
+ \text { RAD }\end{array}$ \\
\hline Madi & 145 & 86.5 & 159.8 & 159.8 & 215.5 & -25.5 & -13.5 & -13.5 & 5.5 & 5.5 \\
\hline Lehar & 138.8 & 352 & 84.8 & 398.6 & 256.1 & -14.5 & -8.5 & -14.5 & -2.5 & -14.5 \\
\hline Phailin & 146.8 & 48.9 & 244.1 & 142 & 244.2 & -5 & -5 & -5 & 1 & 1 \\
\hline Nilam & 9.6 & 149.5 & 85.2 & 58.8 & 32.6 & -16 & -16 & -16 & -10 & -10 \\
\hline Thane & 189.5 & 84.4 & 16.9 & 102.2 & 82.5 & -1 & -7 & -7 & -7 & 11 \\
\hline Laila & 334.5 & 56.6 & 321 & 376.4 & 646.8 & 7 & 13 & 13 & 1 & 13 \\
\hline Jal & 121.2 & 121.2 & 141 & 46.8 & 112.3 & -10 & -16 & -16 & -16 & -16 \\
\hline Khaimuk & 35.6 & & 10.5 & & 59.7 & -10 & & -10 & & 16 \\
\hline Mean error & 140.13 & 128.44 & 132.91 & 183.51 & 206.21 & -9.3 & -7.57 & -8.63 & -4 & 0.75 \\
\hline
\end{tabular}

Table 4. Mean error (ME) and RMSE in simulated rainfall for all eight selected tropical cyclones.

\begin{tabular}{lrr}
\hline Experiment & ME $(\mathrm{mm})$ & RMSE $(\mathrm{mm})$ \\
\hline CTL & 1.15 & 48.30 \\
VARAMV & 5.18 & 32.99 \\
VARRAD & -4.52 & 45.52 \\
VARPREP & -8.06 & 43.8 \\
VARPREP+RAD & -9.91 & 65.49 \\
\hline
\end{tabular}

rainfall during the landfall for each cyclone cases in each experiment.

\section{Conclusions}

Forecasting cyclonic storms is highly important for disaster management in tropical maritime countries and is highly challenging. At the present time, high-resolution mesoscale atmospheric models are used to generate forecasts for TCs in tropical maritime countries. The weather prediction is an initial-boundary value problem. Tropical cyclones in particular are challenging phenomena for meteorological community as sufficient accuracy in initial conditions is rare to obtain due to the scarcity of data over oceanic regions. As the science has advanced, the extraction of a better initial state through data assimilation using all available observation sources has become possible. In this work, we employed the most commonly available surface, upper-air and a few satellite-based observations to study their impact on TC forecasts in WRF using 3D-Var over the BOB of the NIO. Detailed analysis of a recent cyclone, Phailin, reveals that VARPREP improves the track predictions by 5 $40 \%$ in the $24-96 \mathrm{~h}$ forecast range over the CTL using simple downscaling of global model forecasts. This experiment also simulated minimal landfall position and time errors as $80 \mathrm{~km}$ and $4 \mathrm{~h}$ respectively. The intensity predictions are improved in VARPREP and VARPREP+RAD. The representa- tion of structural features is improved in VARPREP+RAD as revealed by comparisons of wind field, azimuthal averages of temperature anomaly and tangential winds from CIRA data and maximum reflectivity from IMD DWR data during landfall. The quantity and spatial distribution of rainfall for Phailin are well simulated by VARRAD and VARPREP+RAD.

The results of all eight recent cyclones in the NIO indicated that local data assimilation using 3D-Var with cyclic mode is superior to the simple approach of downscaling the global model forecasts as seen from substantial improvements in track and intensity estimates for a majority of the cases. However, the success of this method is subject to the availability of quality observations as seen in the case of Laila where the lack of observations created more noise and deteriorated the predictions.

The results of assimilation of mass (radiance) and winds (AMV) have shown different impacts on the TC properties. The assimilation of AMV mainly influenced the track predictions and the intensity predictions are influenced by both motion vectors and radiances. It has been found that the assimilation of AMV substantially improved the track predictions for a few cyclones (Lehar, Madi, Thane and Khaimuk). This could be due to the assimilation of wind information leading to improvements in the representation of the wind field and initial vortex in these cases. However, the improvements are subject to the average coverage of data as seen in the meager impact in predictions for a few cyclone cases. The meager impact on the intensity predictions by motion vectors is obvious from the small changes in model thermodynamics. Experiments with assimilation of AMSU-A and B satellite radiance data pertaining to temperature and moisture profiles have shown a greater impact on the intensity estimates compared to the track forecasts. The improvements in intensity with radiance data (temperature and moisture) are evident due to improvements in the model thermodynamics. Earlier studies (Kalnay et al., 1985; Cress and Wergen, 2001; Horanyi et al., 2014) have reported the importance of wind 
observations compared to mass observations in the tropics in assimilation and forecast systems. The present results show higher impacts of motion vectors relative to radiances in $\mathrm{TC}$ predictions.

Experiments with assimilation of PrepBUFR data show substantial improvements in track prediction for a majority of the cases in addition to improving intensity due to changes in both the vortex and thermodynamics of the atmosphere. Cyclic mode data assimilation with 3D-Var using various observation sources showed best predictions with VARPREP, followed by VARAMV for track positions, VARPREP+RAD for intensity and VARAMV and VARPREP for rainfall. The results of all the experiments clearly show that the PrepBUFR observations which also contain the AMV always have better predictions of both intensity and track relative to those using radiance data, the latter shows an impact only on intensity. Of the eight recent cyclone cases tested, six have shown improvements in both track and intensity with the assimilation of PrepBUFR data. Overall, an improvement of about 3-36\% in track, 6$63 \%$ in central pressure, $26-103 \%$ in maximum tangential winds and $11-223 \%$ in the radius of maximum winds for 24$96 \mathrm{~h}$ lead time forecasts are noted with assimilation of PrepBUFR observations. The forecast improvements are found to be associated with clear changes in the state variables of pressure, wind distribution, temperature and humidity in the initial conditions after data assimilation leading to changes in both dynamics and thermodynamics of the model atmosphere. The better model performance with PrepBUFR observations is due to a combination of various conventional (surface, upper air) and satellite-based observations (motion vectors, ocean surface winds), with a larger effective area coverage than each of constituent observation sources, evident in earlier studies (Srinivas et al., 2010; Yesubabu et al., 2013, 2014). The performance of VARPREP+RAD with the use of all observations (radiance data along with PrepBUFR) is not as good as expected and the errors increased considerably after $72 \mathrm{~h}$. This could be due to the biases in channel-specific radiance data and the inefficiency of current WRF data assimilation system etc., which are ongoing research topics, and the uncertainties are still high (Xu et al., 2013). Another reason for better predictions with assimilation of PrepBUFR data could be the better quality-control procedures in the preparation of PrepBUFR. If PrepBUFR observations are combined with radiance data with bias or noise, the model fields will be tuned towards the biased radiance, which may result in the reduction of the quality of the initial condition. Secondly, while assimilating radiance data, the availability of satellite observations (satellite pass and density of observations) have high priority. The substantial reduction of track errors with the assimilation of operationally available PrepBUFR observations in ARW over the CTLs in the present study is a very encouraging result for operational predictions.
Acknowledgements. The authors thank P. R. Vasudeava Rao, Director of the IGCAR, and S. A. V. Sathya Murty, Director of EIRSG, for their encouragement and support. The GFS analysis and forecasts used in operational predictions are available from the NOMADS server, NOAA, USA. PrepBUFR observations and AMSU$A$ and $B$ radiances data are obtained from CISL Research Data Archive managed by NCAR's data support section. The India Meteorological Department is acknowledged for the use of radar reflectivity images, best track and intensity estimates. The CIRA Tropical cyclone wind analysis are obtained from NOAA/NESDIS/STAR. Authors thank the reviewers for their technical comments which helped to greatly improve the content of the manuscript.

The topical editor V. Kotroni thanks two anonymous referees for help in evaluating this paper.

\section{References}

Aberson, S. D.: The ensemble of tropical cyclone track forecasting models in the North Atlantic Basin (1976-2000), B. Am. Meteorol. Soc., 82, 1895-1904, 2001.

Anthes, R. A.: Tropical cyclones: Their Evolution, Structure and Effects, American Meteorological Society, Ephrata, PA, 208 pp., 1982.

Asnani, G, C.: Tropical Meteorology, Q. J. Roy. Meteor. Soc., 120, 1426-1427, 1994.

Barker, D. M., Huang, W., Guo, Y. R., and Xiao Q. N.: A threedimensional (3-D-Var) data assimilation system for use with MM5: implementation and initial results, Mon. Weather Rev., 132, 897-914, 2004.

Barker, D. M., Huang, X. Y., Liu, Z., Auligne, T., Zhang, X., Rugg, S., Al Katheri, A. A., Bourgeios, A., Bray, J., Chen, Y., Demirtas, M., Guo, Y., Henderson, T., Huang, W., Lin, H. C., Michalakes, J., Rizvi, S., and Zhang, X. Y.: The Weather Research and Forecasting (WRF) Model's Community Variational/Ensemble Data Assimilation System: WRFDA, B. Am. Meteorol. Soc., 93, 831843, 2011.

Braun, S. A, Montgomery, M. T., and Pu, X.: High resolution simulation of hurricane Bonnie (1998), Part I: The organization of eyewall vertical motion, J. Atmos. Sci., 63, 19-42, 2006.

Chen, D. R., Yeh, T. C., Haung, K. N., Peng, M. S., and Chang, S. W.: A new operational typhoon track prediction system at the central weather Bureau in Taiwan, Preprints 21st Conf. Hurr. Trop. Meteor. Soc. Bostan, MA 02108, 50-51, 1995.

Chen, F. and Dudhia, J.: Coupling an advanced landsurface/hydrology model with the Penn State/NCAR MM5 modeling system, Part I: Model description and implementation, Mon. Weather Rev., 129, 569-585, 2001.

Courtier, P., Andersson, E., Heckley, W., Pailleux, J., Vasiljevic, D., Hamrud, M., Hollingsworth, A., Rabier, F., and Fisher, M.: The ECMWF implementation of three dimensional variational assimilation (3-D-Var), I: Formulation, Q. J. R. Meteorol. Soc., 124, 1783-1807, 1998.

Cress, A. and Wergen, W.: Impact of profile observations on the German Weather Service's NWP system, Meteorol. Z., 10, 91101, 2001.

Das, A. K., Rama Rao Y. V., Tallapragada, V., Zhang, Z., Roy Bhowmik, S. K., and Sharma, A.: Evaluation of the Hurricane Weather Research and Forecasting (HWRF) model for tropical 
cyclone forecasts over the North Indian Ocean (NIO), Nat. Hazards, 75, 1205-1221, doi:10.1007/s11069-014-1362-6, 2014.

Davis, C., Wang, W., Chen, S. S., Chen, Y., Corbosiero, K., De Maria, M., Dudhia, J., Holland, G., Klemp, J., Michalakes, J., Reeves, H., Rotunno, R., Snyder, C., and Xiao, Q.: Prediction of landfalling hurricanes with the Advanced Hurricane WRF model, Mon. Weather Rev., 136, 1990-2005, 2008.

Derber, J. C. and Wu, W. S.: The use of TOVS cloud-cleared radiances in the NCEP SSI analysis system. Mon. Wea. Rev., 126, 2287-2299, 1998.

Dudhia, J.: Numerical study of convection observed during winter monsoon experiment using a mesoscale two-dimensional model, J. Atmos. Sci., 46, 3077-3107, 1989.

Fierro, A. O., Rogers, R. F., Marks, F. D., and Nolan, D. S.: The Impact of Horizontal Grid Spacing on the Microphysical and Kinematic Structures of Strong Tropical Cyclones Simulated with the WRF-ARW Model, Mon. Weather Rev., 137, 3717-3743, 2009.

Gentry, M. S. and Lackmann, G. M.: Sensitivity of Simulated Tropical Cyclone Structure and Intensity to Horizontal Resolution, Mon. Weather Rev., 138, 688-704, 2010.

Gopalakrishnan, S. G., Goldenberg, S., Quirino, T., Zhang, X., Marks, F., Yeh, K. S., Atlas, R., and Tallapragada, V.: Toward improving high-resolution numerical hurricane forecasting: Influence of model horizontal grid resolution, initialization, and physics, Wea. Forecast., 27, 647-666, 2012.

Gray, W. M.: Global view of the origin of tropical disturbances and storms, Mon. Weather Rev., 96, 669-700, 1968.

Gray, W. M.: General characteristics of tropical cyclones, in: Storms, edited by: Pielke Jr., R. and Pielke Sr., R., Vol. 1, Routledge, London, UK, 145-163, 2000.

Han, Y., van Delst, P., Liu, Q., Weng, F., Yan, B., Treadon, R., and Derber, J.: Community Radiative Transfer Model (CRTM)Version 1, Tech. Rep. 122, NOAA, Silver Spring, Md, 2006.

Harris, B. A. and Kelly, G.: A satellite radiance-bias correction scheme for data 765 assimilation, Q. J. Roy. Meteor. Soc. 127, 1453-1468, 2001.

Horanyi, A., Cardinali, C., Rennie, M., and Isaksen, L.: The assimilation of horizontal line-of-sight wind information into the ECMWF data assimilation and forecasting system, Part I: The assessment of wind impact, Q. J. Roy. Meteor. Soc., 141, 12231232, doi:10.1002/qj.2430, 2014.

Hong, S. Y., Noh, Y., and Dudhia, J.: A new vertical diffusion package with explicit treatment of entrainment processes, Mon. Weather Rev., 134, 2318-2341, 2006.

Hsiao, L. F., Chen, D. S., Kuo, Y. H., Guo, Y. R., Yeh, T. C., Hong, J. S., Fong, C. T., and Lee, C. S.: Application of WRF 3DVAR to Operational Typhoon Prediction in Taiwan: Impact of Outer Loop and Partial Cycling Approaches, Wea. Forecasting, 27, 1249-1263, 2012.

Huffman, G. J., Bolvin, D. T., Nelkin, E. J., Wolff, D. B., Adler, R. F., Gu, G., Hong, Y., Bowman, K. P., and Stocker, E. F.: The TRMM Multisatellite Precipitation Analysis (TMPA): Quasi-Global, Multiyear, Combined-Sensor Precipitation Estimates at Fine Scales, J. Hydrometeorol., 8, 38-55, doi:10.1175/JHM560.1, 2007.

Ide, K., Courtier, P., Ghil, M., and Lorenc, A. C.: Unified notation for data assimilation: operational, sequential and variational, J. Met. Soc. Japan, 75, 181-189, 1997.
India Meteorological Department: Report on cyclonic disturbances over North Indian Ocean during 2008, RSMC-Tropical Cyclone Report No. 1/2009, IMD, New Delhi, India, 108 pp., 2009.

India Meteorological Department: Report on cyclonic disturbances over North Indian Ocean during 2009, RSMC- Tropical Cyclone Report No. 1/2010, IMD, New Delhi, India, 122 pp., 2010.

India Meteorological Department: Report on cyclonic disturbances over North Indian Ocean during 2010, RSMC- Tropical Cyclone Report No. 1/2011, IMD, New Delhi, India, 162 pp., 2011.

India Meteorological Department: Report on Cyclonic Disturbances over North Indian Ocean during 2011, RSMC-Tropical Cyclones Report No. 02 (2012) IMD, New Delhi, India, 186 pp., 2012.

India Meteorological Department: Report on Cyclonic Disturbances over North Indian Ocean during 2012, Met. Monograph No. ESSO/IMD/RSMC-Tropical Cyclones Report No. 01 (2013) IMD, New Delhi, India, 214 pp., 2013.

India Meteorological Department: Report on Cyclonic Disturbances over North Indian Ocean during 2013, Met. Monograph No. ESSO/IMD/RSMC-Tropical Cyclones Report No. 01 (2014) IMD, New Delhi, India, 274 pp., 2014.

Jiang, X., Zhong, Z., and Liu, C.: The Effect of Typhoon-Induced SST Cooling on Typhoon Intensity: The Case of Typhoon Chanchu (2006), Adv. Atmos. Sci., 25, 1062-1072, 2008.

Kain, J. S.: The Kain-Fritsch convective parameterization: An update, J. Appl. Meteor., 43, 170-181, 2004.

Kalnay, E.: Atmospheric Modeling, Data Assimilation and Predictability, Cambridge University Press, 364 pp., 2003.

Kalnay, E., Jusem, J. C., and Pfaendtner, J.: The relative importance of mass and wind data in the FGGE observing system, in: Proceedings of the NASA Symposium on Global Wind Measurements, Columbia, MD, edited by: Baker, W. E. and Curran, R. J., NASA, Washington, DC, 1-5, 1985.

Keyser, D.: PREPBUFR Processing at NCEP, available at http://www.emc.ncep.noaa.gov/mmb/data_processing/prepbufr. doc/document.htm, 2010.

Kim, Y. H., Jeon, E. H., Chang, D. E., Lee, H. S., and Park, J. I.: The impact of TPARC 2008 dropsonde observations on typhoon track forecasting, Asia-Pac. J. Atmos. Sci., 46, 287-303, 2010.

Knaff, J. A., DeMaria, M., Molenar, D. A., Sampsonand, C. R., and Seybold, M. G.: An automated objective, multiple-satelliteplatform tropical cyclone surface wind analysis, J. Appl. Meteorol. Climatol., 50, 2149-2166, 2011.

Krishna, K. O., Routray, A., Mohanty, U. C., and Kulkarni, M. A.: Simulation of Tropical Cyclones Over Indian Seas: Data Impact Study Using WRF-Var Assimilation System, Indian Ocean Tropical Cyclones and Climate Change, edited by: Charabi, Y., Springer Netherlands (Book Chapter), 115-124, doi:10.1007/978-90-481-3109-9_15, 2010.

Krishna, K. O., Mohanty, U. C., Routray, A., and Mohapatra, M.: The impact of satellite-derived wind data assimilation on track, intensity and structure of tropical cyclones over the North Indian Ocean, Int. J. Remote Sens., 33, 1627-1652, doi:10.1080/01431161.2011.596849, 2012.

Krishnamurti, T. N., Pattnaik, S., Stefanova, L., Vijaya Kumar, T. S. V., Mackey, B. P., O'Shay, A. J., and Richard, J. P.: The Hurricane Intensity Issue, Mon. Weather Rev., 133, 1886-1912, 2005.

Kuni, M., Shoji, Y., Ueno, M., and Saito, K.: Mesoscale Data Assimilation of Myanmar Cyclone Nargis, J. Meteorol. Soc. Japan, 88, 455-474, 2010. 
Kurihara, Y., Tuleya, R. E., and Bender, M. A.: The GFDL hurricane prediction system and its performance in the 1995 hurricane season, Mon. Weather Rev., 128, 1306-1322, 1998.

Lin, Y. L., Farley, R. D., and Orville, H. D.: Bulk parameterization of the snow field in a cloud model, J. Climate Appl. Meteor., 22, 1065-1092, 1983.

Liu, Y., Zhang, D. L., and Yau, M. K.: A multi-scale numerical simulation of hurricane Andrew (1992), Part I: Explicit simulation and verification, Mon. Weather Rev., 125, 3073-3093, 1997.

Liu, Z. Q. and Barker, D. M.: Radiance assimilation in WRF-Var: Implementation and initial results, paper presented at 7th WRF Users' Workshop, NCAR, Boulder, CO, available at: http://www.mmm.ucar.edu/wrf/users/workshops/ WS2006/abstracts/Session04/4_2_Liu.pdf, 2006.

Liu, Z., Schwartz, C. S., Snyder, C., and Ha, S.-Y.: Impact of assimilating AMSU-A radiances on forecasts of 2008 Atlantic tropical cyclones initialized with a limited-area ensemble Kalman filter, Mon. Weather Rev., 140, 4017-4034, 2012.

Marks, F. D. and Shay, L. K.: Landfalling tropical cyclones: Forecast problems and associated research opportunities, B. Am. Meteorol. Soc., 79, 305-323, 1998.

McNoldy, B., De Maria, M., Tallapragada, V., and Marchock, T.: WRF performance diagnostics form the 2009 Atlantic hurricane season, Preprints, American Meteorological Society 29th Conference on Hurricanes and Tropical Meteorology, Tucson, AZ, 11 May 2010.

Mlawer, E. J., Taubman, S. J., Brown, P. D., Iacono, M. J., and Clough, S. A.: Radiative transfer for inhomogeneous atmosphere: RRTM, a validated correlated-k model for the longwave, J. Geophys. Res., 102, 16663-16682, 1997.

Nolan, D. S., Zhang, J. A., and Stern, D. P.: Evaluation of Planetary Boundary Layer Parameterizations in Tropical Cyclones by Comparison of In Situ Observations and High-Resolution Simulations of Hurricane Isabel (2003), Part I: Initialization, Maximum Winds, and the Outer-Core Boundary Layer, Mon. Weather Rev., 137, 3651-3674, 2009.

Park, S. K., Zhang, D. L., and Kim, H. H.: Impact of dropwindsonde data on the track forecasts of a tropical cyclone: an observingsystems simulation experiment study, Asia-Pac J. Atmos. Sci., 44, 85-92, 2008.

Parrish, D. F. and Derber, J. C.: The National Meteorological Center's Spectral Statistical Interpolation analysis system, Mon. Weather Rev., 120, 1747-1763, 1992.

Pattanaik, S. and Rama Rao, Y. V.: Track prediction of very severe cyclone "Nargis" using high resolution weather research forecasting (WRF) model, J. Earth Syst. Sci., 118, 309-329, 2009.

Prasad, K. and Rama Rao, Y. V.: Simulation Studies on Cyclone Track Prediction by Quasi-Lagrangian Model (QLM) in Some Historical and Recent Cases in the Bay of Bengal, Using Global Re-analysis and Forecast Grid Point Data Sets, SMRC-No15, SAARC Meteorological Research Centre, Dhaka, Bangladesh, 2006.

Prashant, K., Harishkumar, K. P., and Pal, P. K.: Impact of Oceansat2 Scatterometer Winds and TMI Observations on Phet Cyclone Simulation, 51, 3774-3779, doi:10.1109/TGRS.2012.2221720, 2012.

$\mathrm{Pu}, \mathrm{Z}$ : Assimilation of satellite data in improving numerical simulation of tropical cyclones: progress, challenge and development, in: Data assimilation for atmospheric, oceanic and hydrologic ap- plications, edited by: Park, S. K. and Xu, L., Springer, Berlin, 163-176, 2009.

Raghavan, S. and Sen, A. K.: Tropical cyclone impacts in India and neighbourhood, in: Storms, edited by: Pielke Jr., R. and Pielke Sr., R., Vol. 1, Routledge, London, UK, 339-356, 2000.

Raju, P. V. S., Potty, J., and Mohanty, U. C.: Prediction of severe tropical cyclones over the Bay of Bengal during 2007-2010 using high-resolution mesoscale model, Nat. Hazards, 63, 13611374, 2012.

Rakesh, V. and Goswami, P.: Impact of background error statistics on forecasting of tropical cyclones over the north Indian Ocean, J. Geophys. Res., 116, D20130, doi:10.1029/2011JD015751, 2010.

Rama Rao, Y. V., MadhuLatha, A., and Suneetha, P.: Evaluation of the WRF and Quasi-Lagrangian Model (QLM) for Cyclone Track Prediction Over Bay of Bengal and Arabian Sea, Indian Ocean Tropical Cyclones and Climate Change, Springer, the Netherlands (Book Chapter), doi:10.1007/978-90-481-31099_14, 2010.

Rogers, R., Chen, S., Tenerelli, J., and Willoughby, H.: A numerical study of the impact of vertical shear on the distribution of rainfall in Hurricane Bonnie (1998), Mon. Weather Rev., 131, 1577-1599, 2003.

Routray, A., Mohanty, U. C., and Krishna, K. O.: Impact of Radiance Data Assimilation on Simulation of Tropical Cyclone Thane Using WRF-3-D-VarModelling System, in: Monitoring and Prediction of Tropical Cyclones in the Indian Ocean and Climate Change, edited by: Mohanty, U. C., Mohapatra, M., Singh, O. P., Bandyopadhyay, B. K., Rathore, L. S., 385-395, 2014.

Roy Bhowmik, S. K.: Operational Numerical Weather Prediction (NWP) System of IMD, available at: http://www.imd.gov.in/doc/ nwpsystem.pdf, 2013.

Singh, R., Pal, P. K., Kishtawal, C. M., and Joshi, P. C.: The impact of variational assimilation of SSM/I and QuikSCAT Satellite observations on the Numerical Simulation of Indian Ocean Tropical Cyclones, Wea. Forecasing, 23, 460-476, 2008.

Singh, R., Kishtawal, C. M., Pal, P. K., and Joshi, P. C.: Assimilation of the multisatellite data into the WRF model for track and intensity simulation of the Indian Ocean tropical cyclones, Meteorol. Atmos. Phys, 111, 103-119, 2011.

Singh, R., Prashant, K., and Pal, P. K.: Assimilation of Oceansat-2Scatterometer-Derived Surface Winds in the Weather Research and Forecasting Model, IEEE Trans. Geosci. Remote Sens., 50, 1015-1021, 2012a.

Singh, R., Kishtawal, C. M., Pal, P. K., and Joshi, P. C.: Improved tropical cyclone forecasts over north Indian Ocean with direct assimilation of AMSU-A radiances, Meteorol. Atmos. Phys., 115, 15-34, $2012 b$.

Singh, R., Ojha, S. P., Kishtawal, C. M., and Pal, P. K.: Quality assessment and assimilation of Megha-Tropiques SAPHIR radiances into WRF assimilation system, J. Geophys. Res. Atmos., 118, 6957-6969, doi:10.1002/jgrd.50502, 2013.

Skamarock, W. C., Klemp, J. B., Dudhia, J., Gill, D. O., Barker, D. M., Dudha, M. G., Huang, X., Wang, W., and Powers, Y.: A description of the Advanced Research WRF Ver.30.NCAR Technical Note, NCAR/TN-475+STR, Mesocale and Microscale Meteorology Davison, National Centre for Atmospheric Research, Boulder, CO, USA, 113 pp., 2008. 
Smith, R. K. and Thomsen, G. L.: Dependence of tropical-cyclone intensification on the boundary layer representation in a numerical model, Q. J. R. Meteorol. Soc., 36, 1671-1685, 2010.

Srinivas, C. V., Venkatesan, R., Vesubabu, V., and Nagaraju, C.: Impact of assimilation of conventional and satellite meteorological observations on the numerical simulation of a Bay of Bengal Tropical Cyclone of Nov 2008 near Tamilnadu using WRF model, Meteor. Atmos. Phys., 110, 19-44, 2010.

Srinivas, C. V., Yesubabu, V., Venkatraman, B., and Ramakrishna, S. S. V. S.: Numerical simulation of Cyclonic Storms FANOOS, NARGIS with assimilation of conventional and satellite observations using 3-D-VAR, Nat. Hazards, 63, 867-889, 2012.

Srinivas, C. V., BhaskarRao, D. V., Yesubabu, V., Baskaran, R., and Venkatraman, B.: Tropical cyclone predictions over the Bay of Bengal using the high-resolution advanced research weather research and forecasting model, Q. J. R. Meteorol. Soc., 139, 1810-1825, doi:10.1002/qj.2064, 2013a.

Srinivas, C. V., Yesubabu, V., Ramakrishna, S. S. V. S., and Venkatraman, B.: Real-Time prediction of a severe cyclone "Jal" over Bay of Bengal using a high resolution mesoscale model WRF (ARW), Nat. Hazards, 65, 331-357, doi:10.1007/s11069-0120364-5, 2013b.

Tallapragada, V., Kieu, C., Kwon, Y., Trahan, S., Liu, Q.-F., Zhang, Z., and Kwon, I.-H.: Evaluation of Storm Structure from the Operational HWRF Model during 2012 Implementation, Mon. Weather Rev., 142, 4308-4325, 2014.

Tyagi, A., Bandyopadhyay, B. K., and Mohapatra, M.: Monitoring and prediction of Cyclonic Disturbances over North Indian Ocean by Regional Specialized Meteorological Centre, New Delhi (India): Problems and Prospective, Indian Ocean Tropical Cyclones and Climate Change, Springer the Netherlands (Book Chapter), doi:10.1007/978-90-481-3109-9_12, 2010.

Wang, Y.: An Explicit Simulation of Tropical Cyclones with a Triply Nested Movable Mesh Primitive Equation Model: TCM3, Part I: Description of the model and control experiment, Mon. Wea. Rev., 130, 3022-3036, 2001.
World Meteorological Organization (WMO): Tropical cyclone operational plan for the Bay of Bengal and Arabian Sea, World Meteorological Organization Tech. Tropical Cyclone Programme Rep. TCP-21, WMO/TD-84, available at: http://www.wmo.int/ pages/prog/www/tcp/documents/TCP-21_2011final.pdf, 97 pp., 2011.

Wu, C. C., Chou, K. H., Lin, P. H., Aberson, S. D., Peng, M. S., and Nakazawa, T.: The impact of dropwindsonde data on typhoon track forecast in DOTSTAR, Wea. Forecast., 22, 11571176, 2007.

Xiao, Q., Zhang, X., Davis, C., Tuttle, J., Holland, G., Patrick, J., and Fitzpatrick, P. J.: Experiments of Hurricane Initialization with Airborne Doppler Radar Data for the Advanced-research Hurricane WRF (AHW) Model, Mon. Weather Rev., 137, 27582777, doi:10.1175/2009MWR2828.1, 2009.

Xu, D., Liu, Z., Huang, X.-Y., Min, J., and Wang, H.: Impact of assimilating IASI radiance observations on forecasts of two tropical cyclones, Meteorol. Atmos. Phys., 122, 1-18, 2013.

Yeh, K. S., Zhang, X., Gopalakrishnan, S., Aberson, S., Rogers, R., Marks, F. D., and Atlas, R.: Performance of the experimental HWRF in the 2008 hurricane season, Nat. Hazards, 63, 14391449, doi:10.1007/s11069-011-9787-7, 2012.

Yesubabu, V., Srinivas, C. V., Hariprasad, K. B. R. R., and Baskaran, R.: A study on the Impact of Observation Assimilation on the Numerical Simulation of Tropical Cyclones Jal and Thane using 3-D-Var, Pure Appl. Geophys., 171, 2023-2042, doi:10.1007/s00024-013-0741-3, 2013.

Yesubabu, V., Srinivas, C. V., Hari Prasad, K. B. R. R., and Ramakrishna, S. S. V. S.: Impact of Variational Data Assimilation for Simulating Tropical Cyclones over Bay of Bengal Using WRFARW, in: Monitoring and Prediction of Tropical Cyclones in the Indian Ocean and Climate Change, edited by: Mohanty, U. C., Mohapatra, M., Singh, O. P., Bandyopadhyay, B. K., Rathore, L. S., 236-245, 2014.

Zhang, X., Quirino, T. S., Gopalakrishnan, S., Yeh, K. S., Marks, F. D., and Goldenberg, S. B.: HWRFX: Improving hurricane forecasts with high resolution modeling, Comput. Sci. Eng., 13, 13$21,2011$. 